Nickel-Catalyzed Electrochemical Cyclization of Alkynyl Aryl Iodide, and Domino Reaction with Aldehydes

Claire Déjardin, Amaury Renou, Jacques Maddaluno, and Muriel Durandetti*

Normandie Univ, UNIROUEN, INSA Rouen, CNRS, COBRA (UMR 6014 \& FR 3038)

76000 Rouen, France.

*Corresponding Author: muriel.durandetti@univ-rouen.fr

\title{
Contents
}

${ }^{1} \mathrm{H},{ }^{13} \mathrm{C}\left\{{ }^{1} \mathrm{H}\right\}$ NMR spectra of all new compounds $\mathrm{S} 2$ 
อั

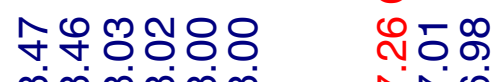

๑

$\checkmark$ iर

$1 \mathrm{e}$
$300 \mathrm{MHz} \quad \mathrm{CDCl}_{3}$

$\underbrace{\circ 95 \infty}$

œ

r<smiles>CC#CCOc1ccc(C(=O)OC)cc1I</smiles>

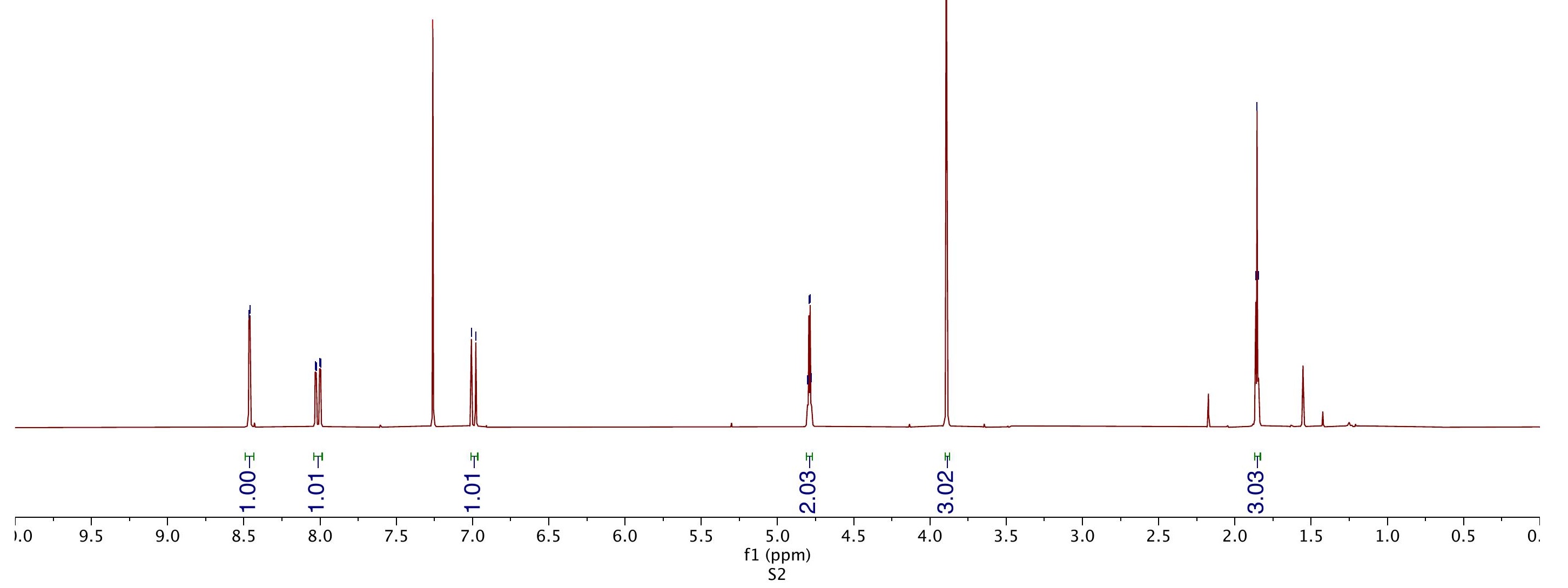


$75 \mathrm{MHz} \quad \mathrm{CDCl}_{3} \frac{m}{\mathrm{~N}} \frac{m}{\mathrm{~N}}$

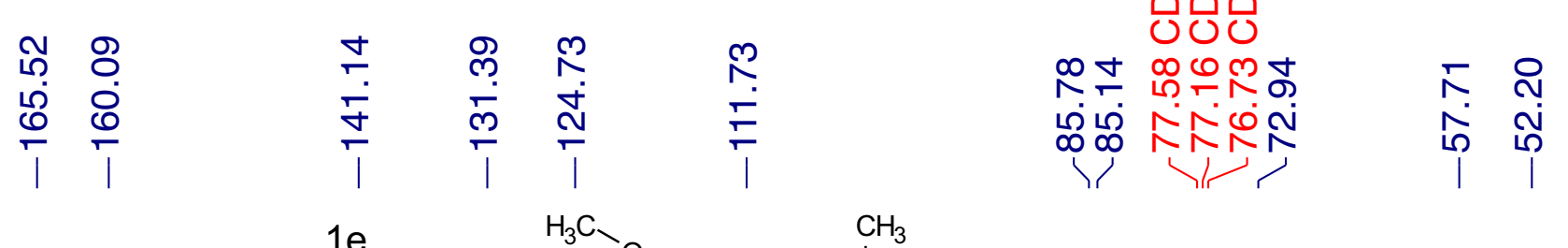<smiles>CC#CCOc1ccc(C(=O)OC)cc1I</smiles>

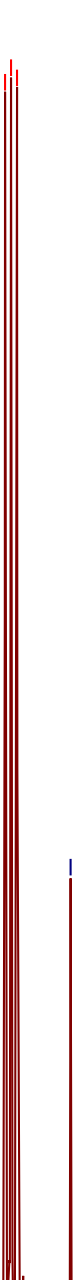




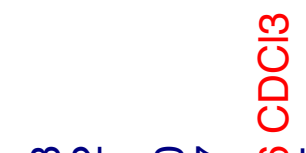

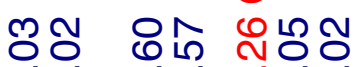

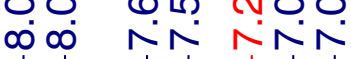

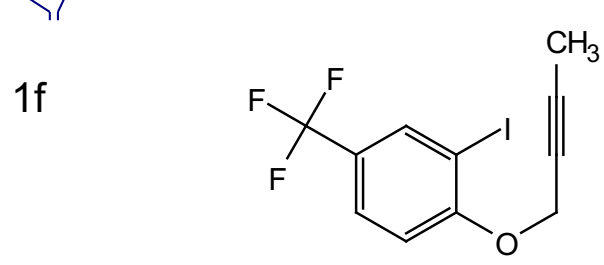

$300 \mathrm{MHz} \quad \mathrm{CDCl}_{3}$

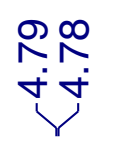

مิ

广

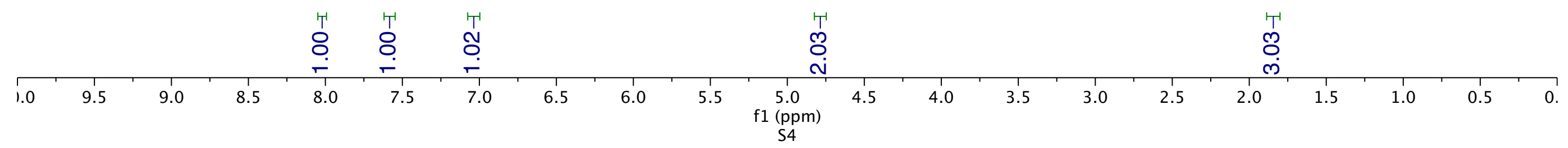




\section{$75 \mathrm{MHz} \quad \mathrm{CDCl}_{3} \frac{m}{\mathrm{O}} \frac{\mathrm{m}}{\mathrm{O}} \frac{\mathrm{m}}{\mathrm{O}}$}

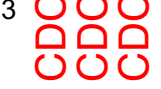

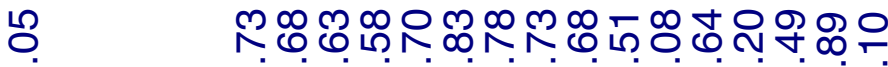

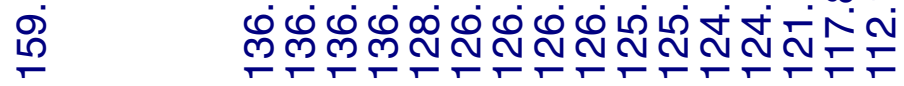

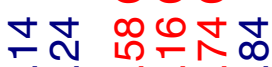

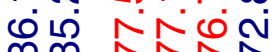

ז.

$\infty \infty$ NरN
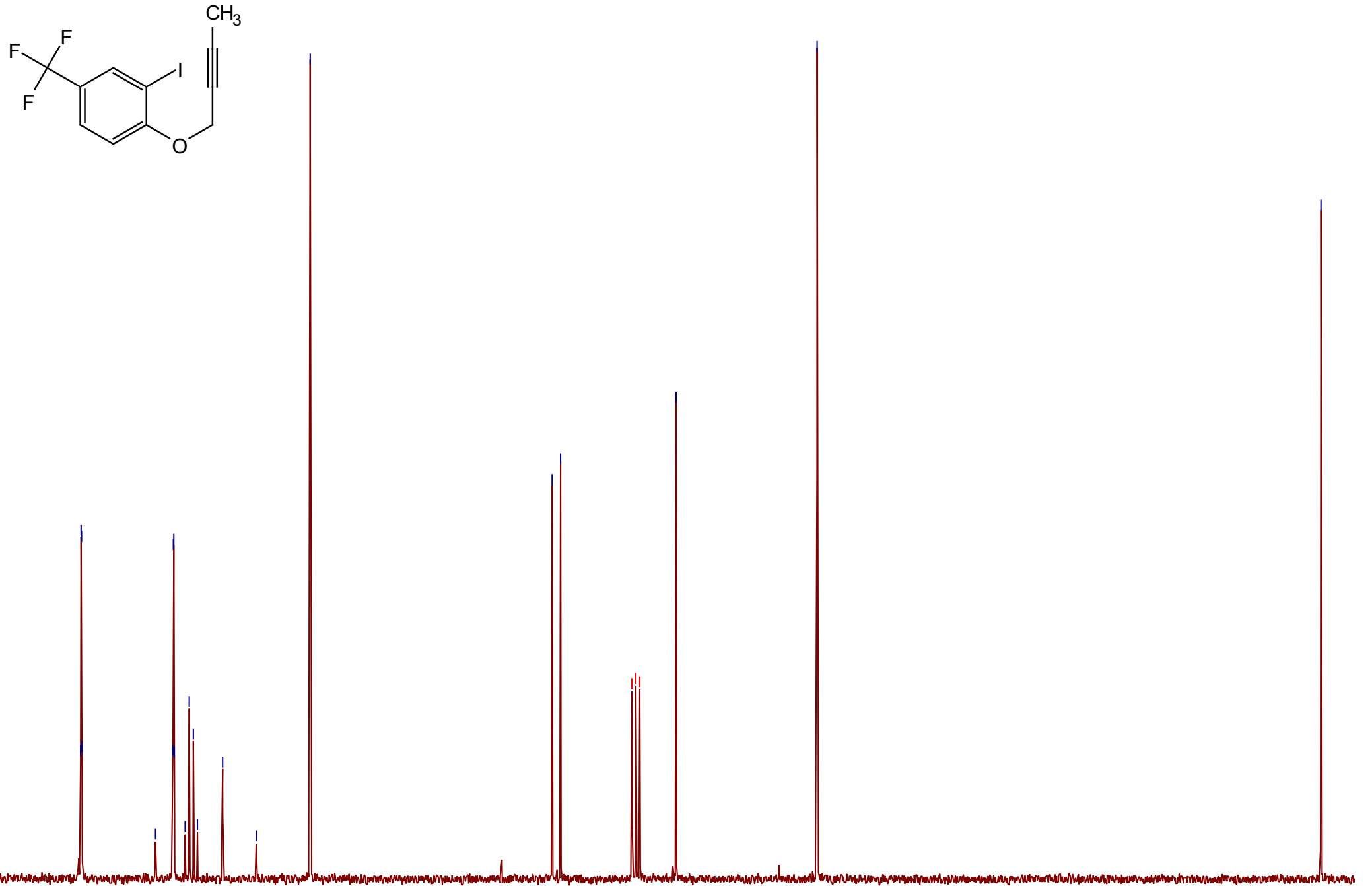


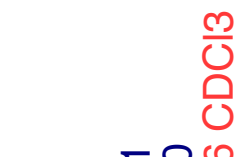

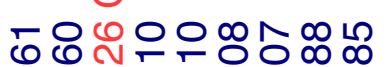

NNNNNNG6

$\checkmark>>1$

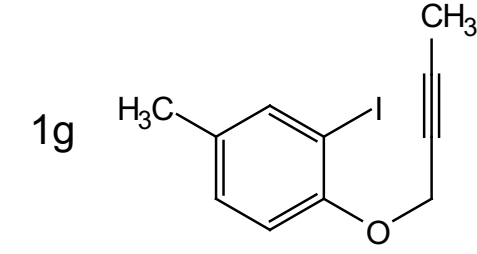

$300 \mathrm{MHz} \quad \mathrm{CDCl}_{3}$

\%ิ

ن

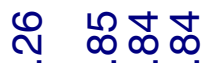

ก

\section{列}


$75 \mathrm{MHz} \quad \mathrm{CDCl}_{3} \frac{m}{\mathrm{U}} \frac{\mathrm{m}}{\mathrm{v}} \frac{\mathrm{m}}{\mathrm{O}}$

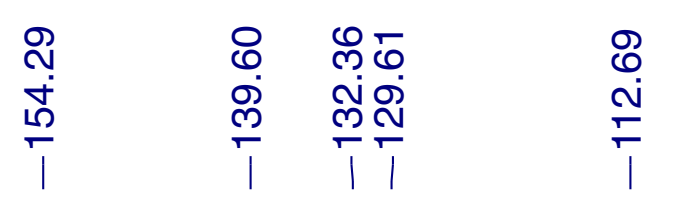
ชิน์

+

ஸ்

$\infty$ 舟

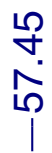

$1 \mathrm{~g}$<smiles>CC#CCOc1ccc(C)cc1I</smiles>
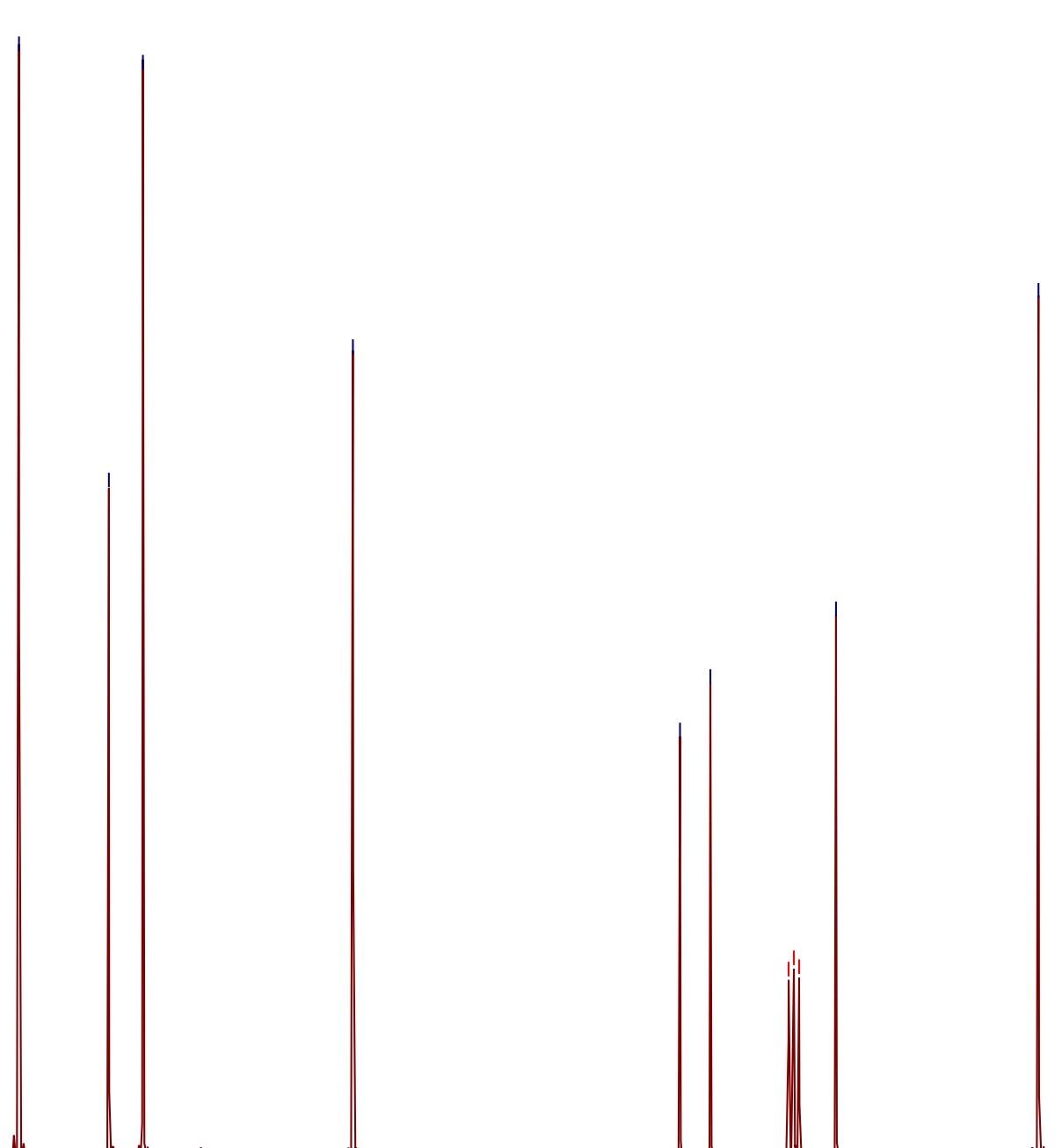
$2 a$<smiles>CC(=C1COc2ccccc21)C(O)c1ccccc1</smiles>

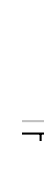
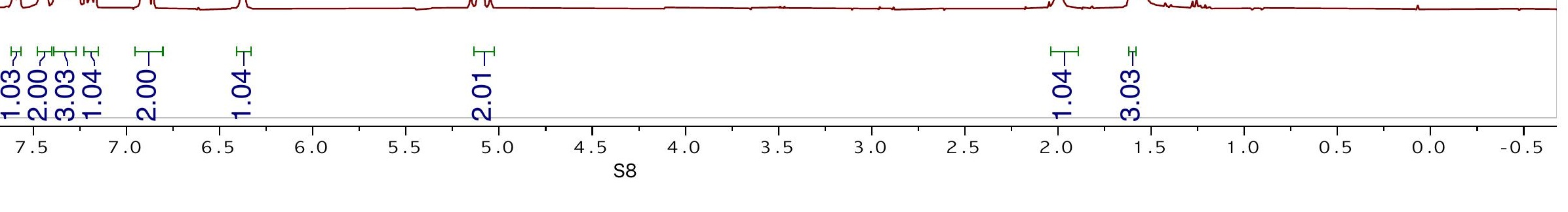
鱼

テ

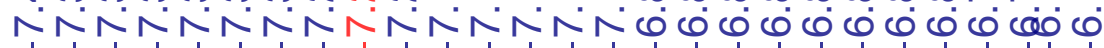

1

$2 b$

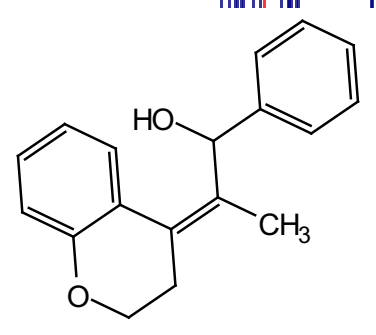

$300 \mathrm{MHz} \quad \mathrm{CDCl}_{3}$

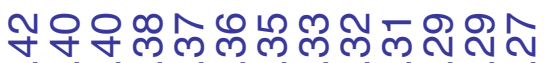

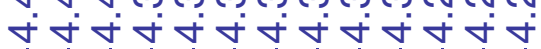

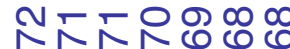

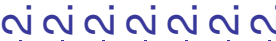

வேஷ í

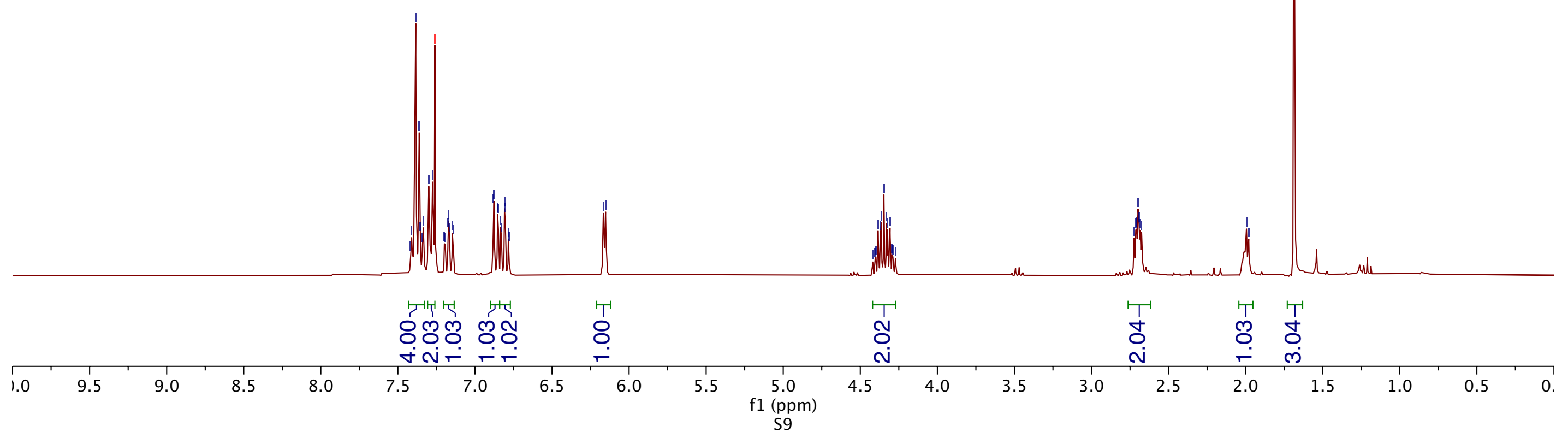


$75 \mathrm{MHz} \quad \mathrm{CDCl}_{3}$

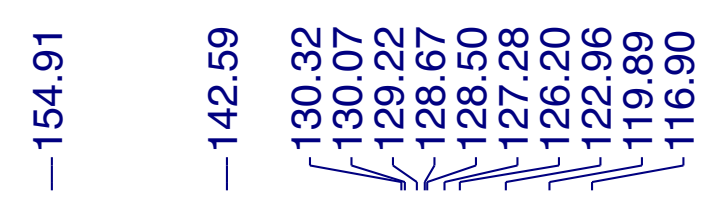

$2 b$
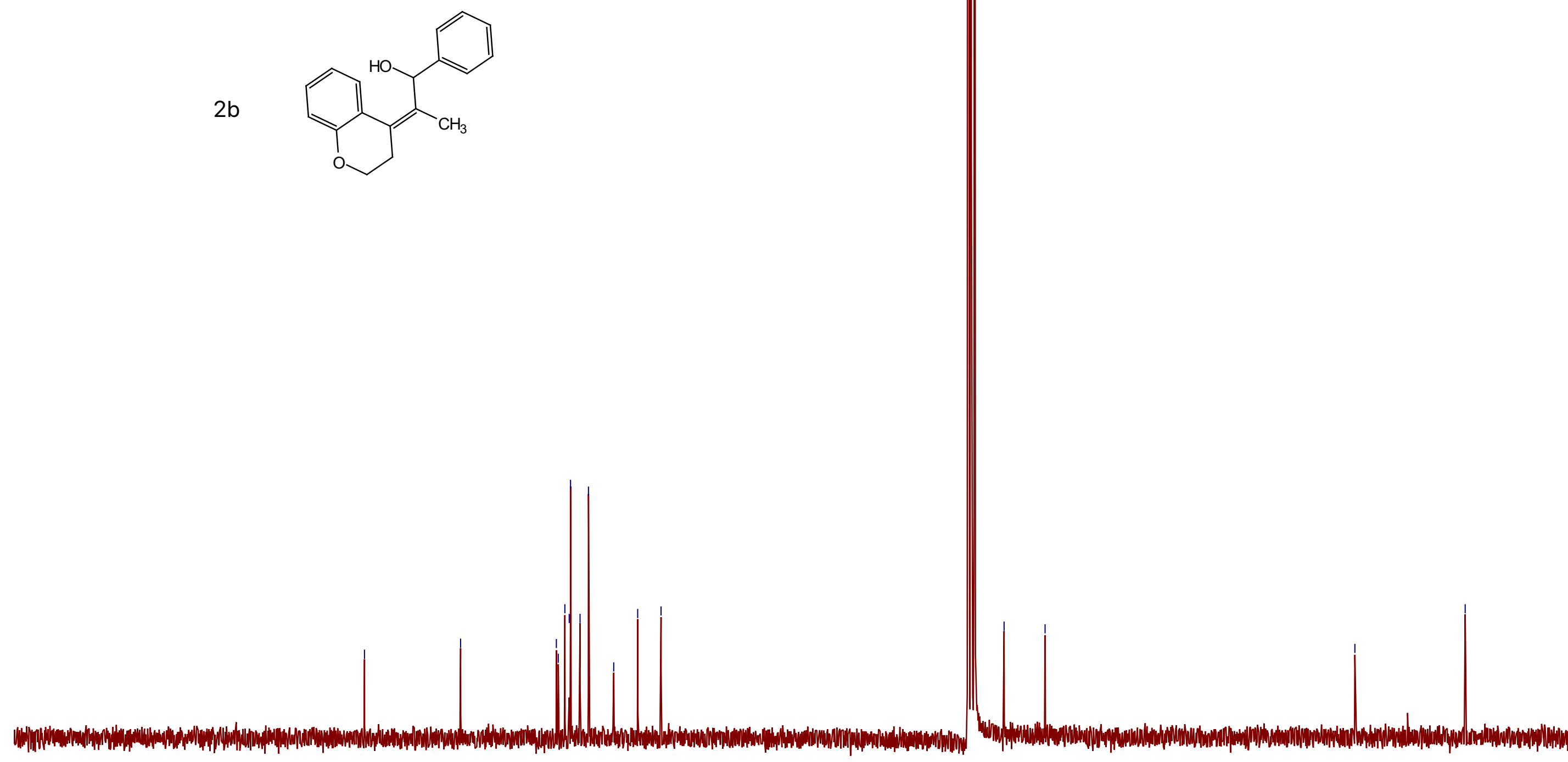
Sळळ

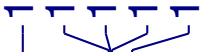

2c
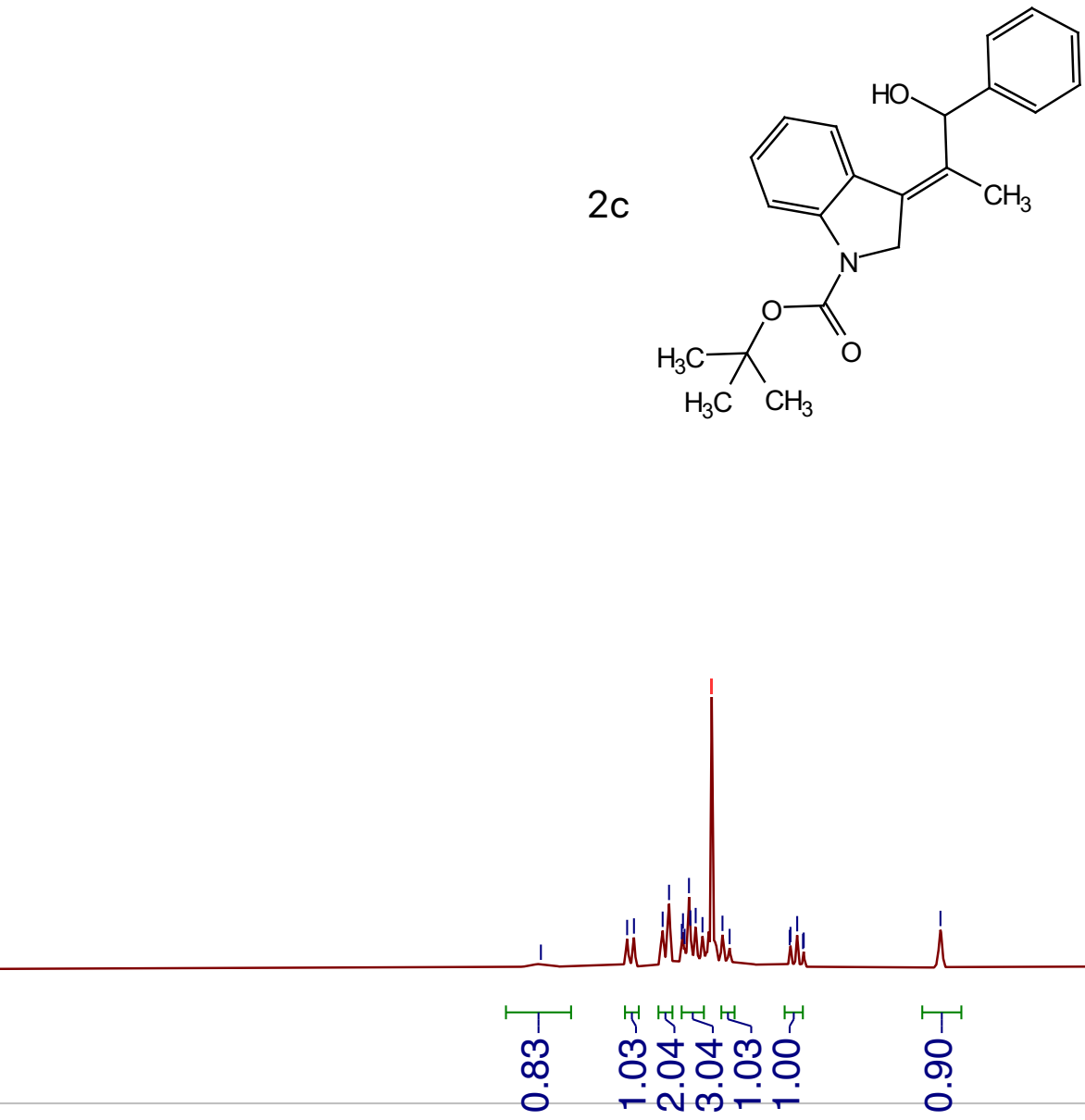

กั. 


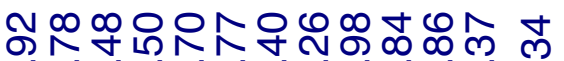

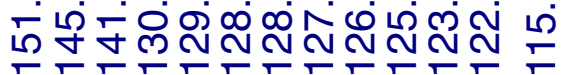

等

$2 c$

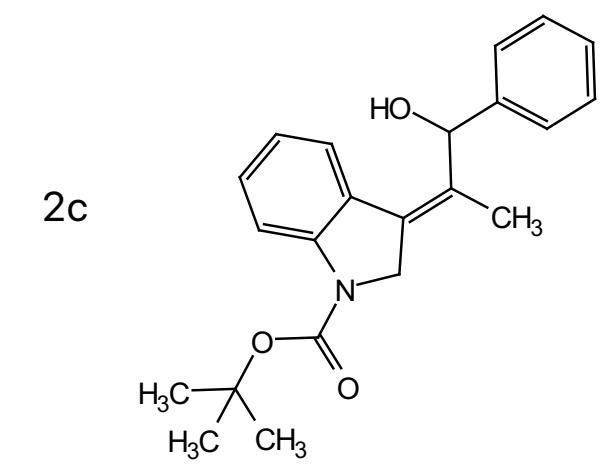

$\frac{m}{0}$ 댕

号戴

눈요 8

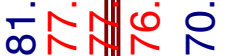

舟

กุ

$\overbrace{\infty}^{\infty} \frac{1}{1}$
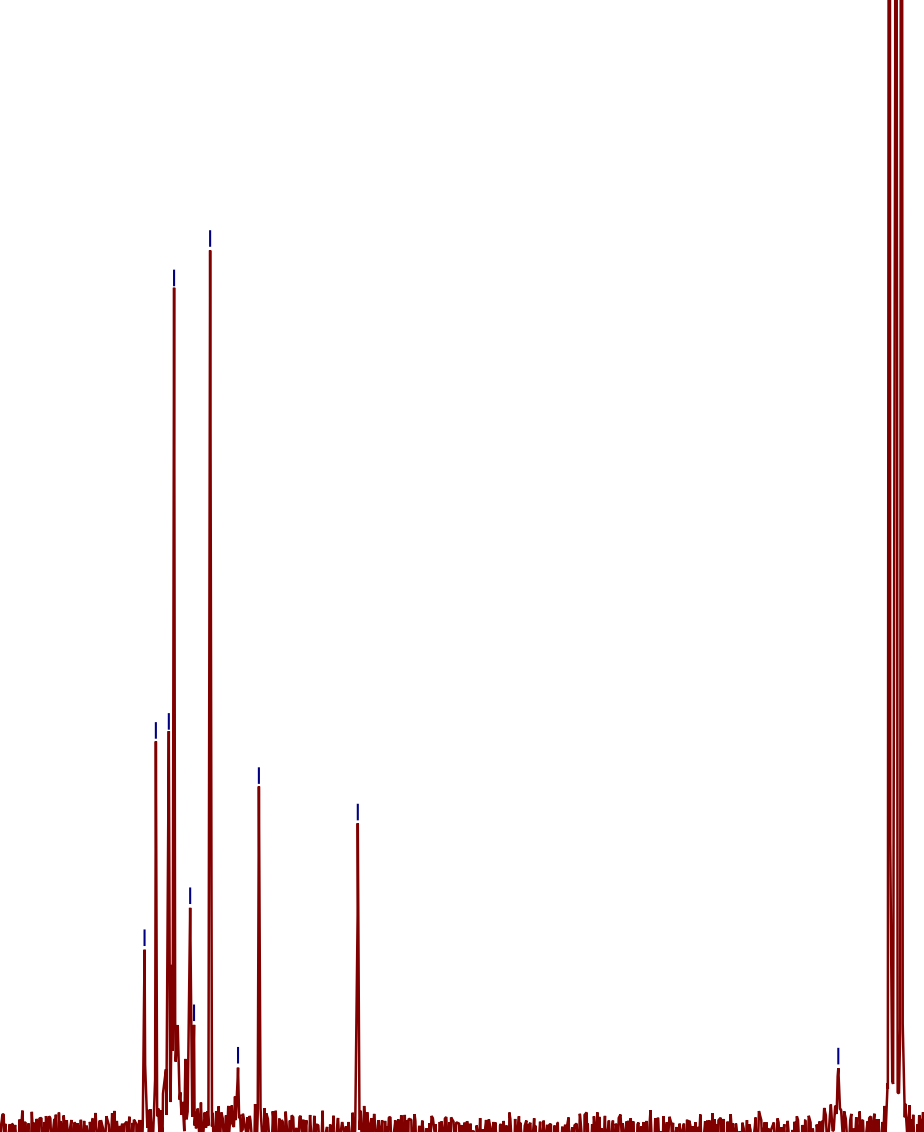

i 
ஜ

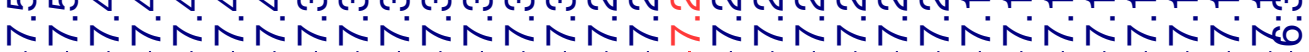

$2 d$
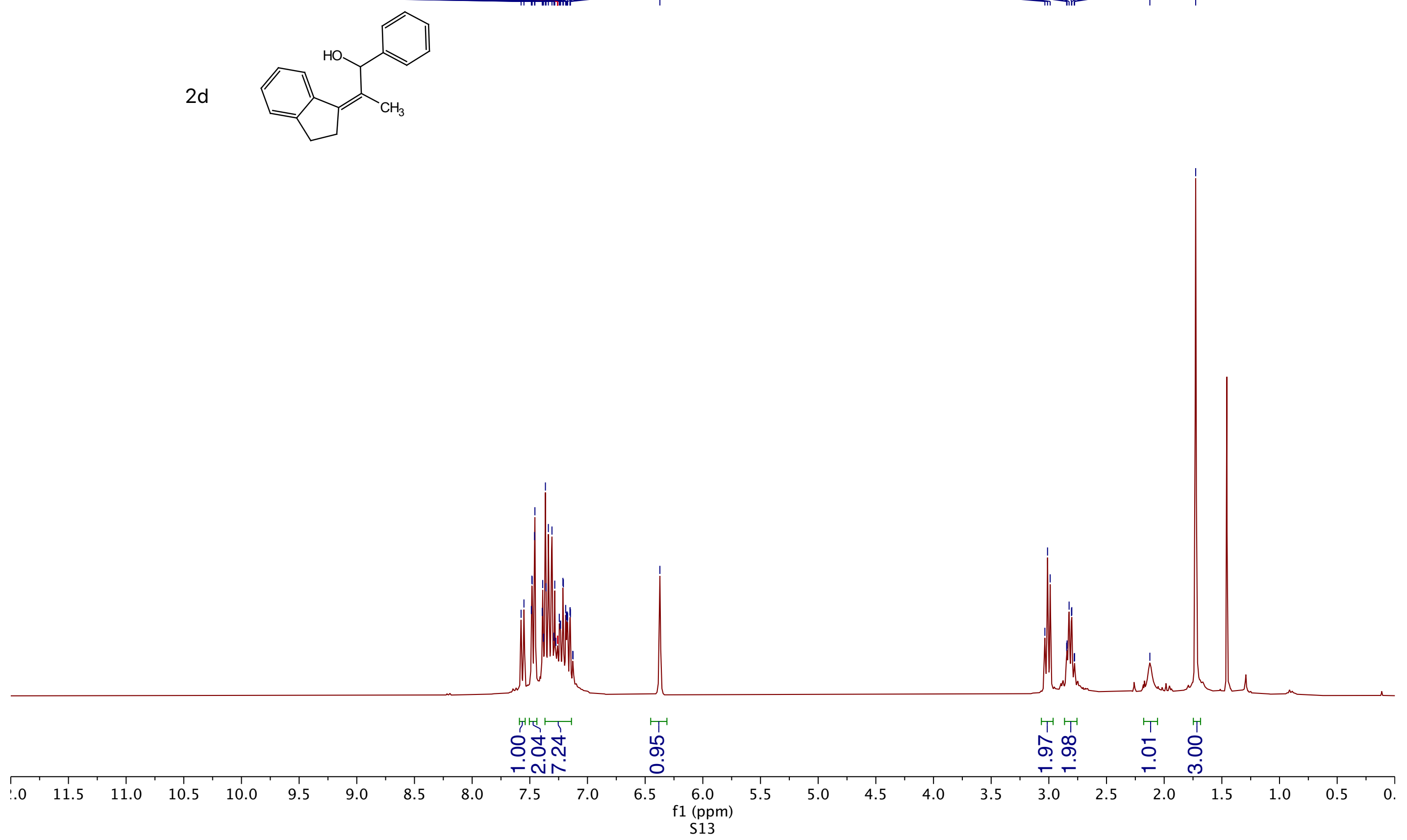
$75 \mathrm{MHz}-\mathrm{CDCl}_{3}$

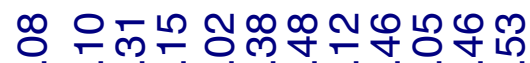

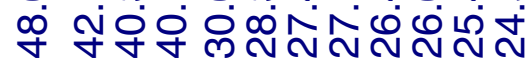

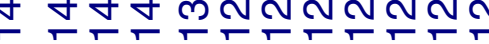

广र

$2 d$

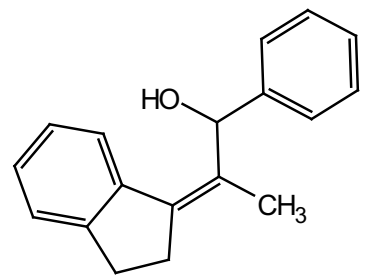

$\frac{m}{0} \frac{m}{0} \frac{m}{c}$

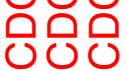

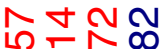

ペ゚์

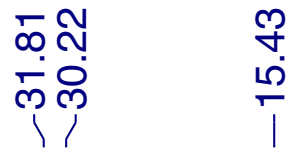
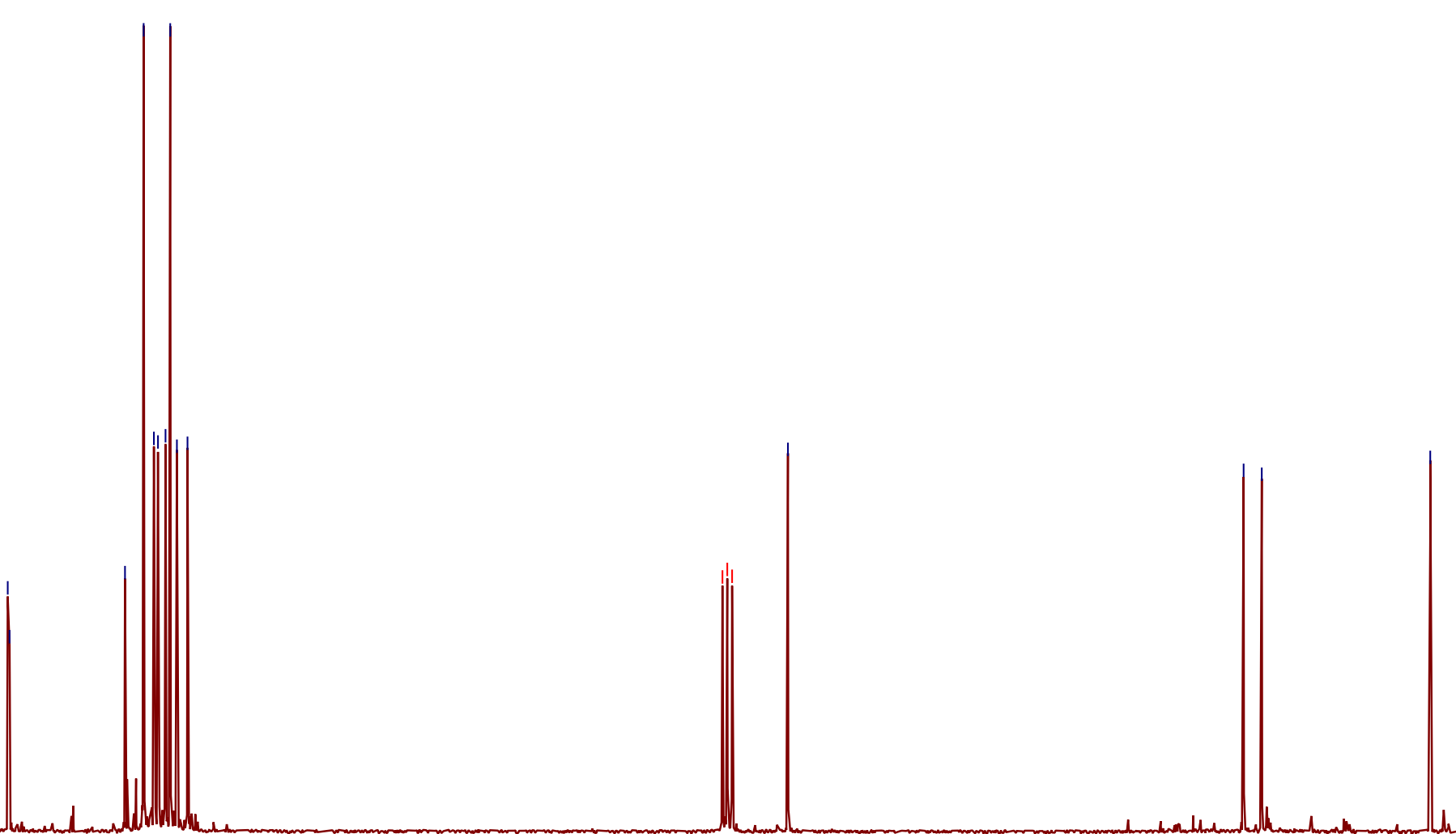


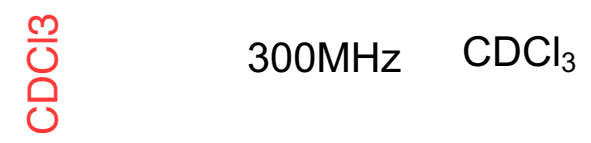

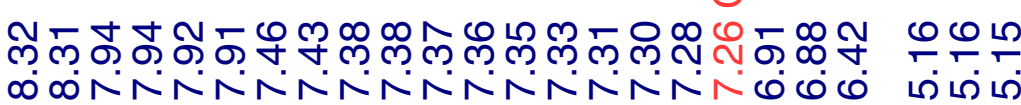

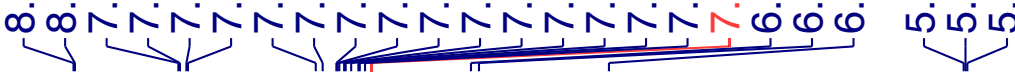

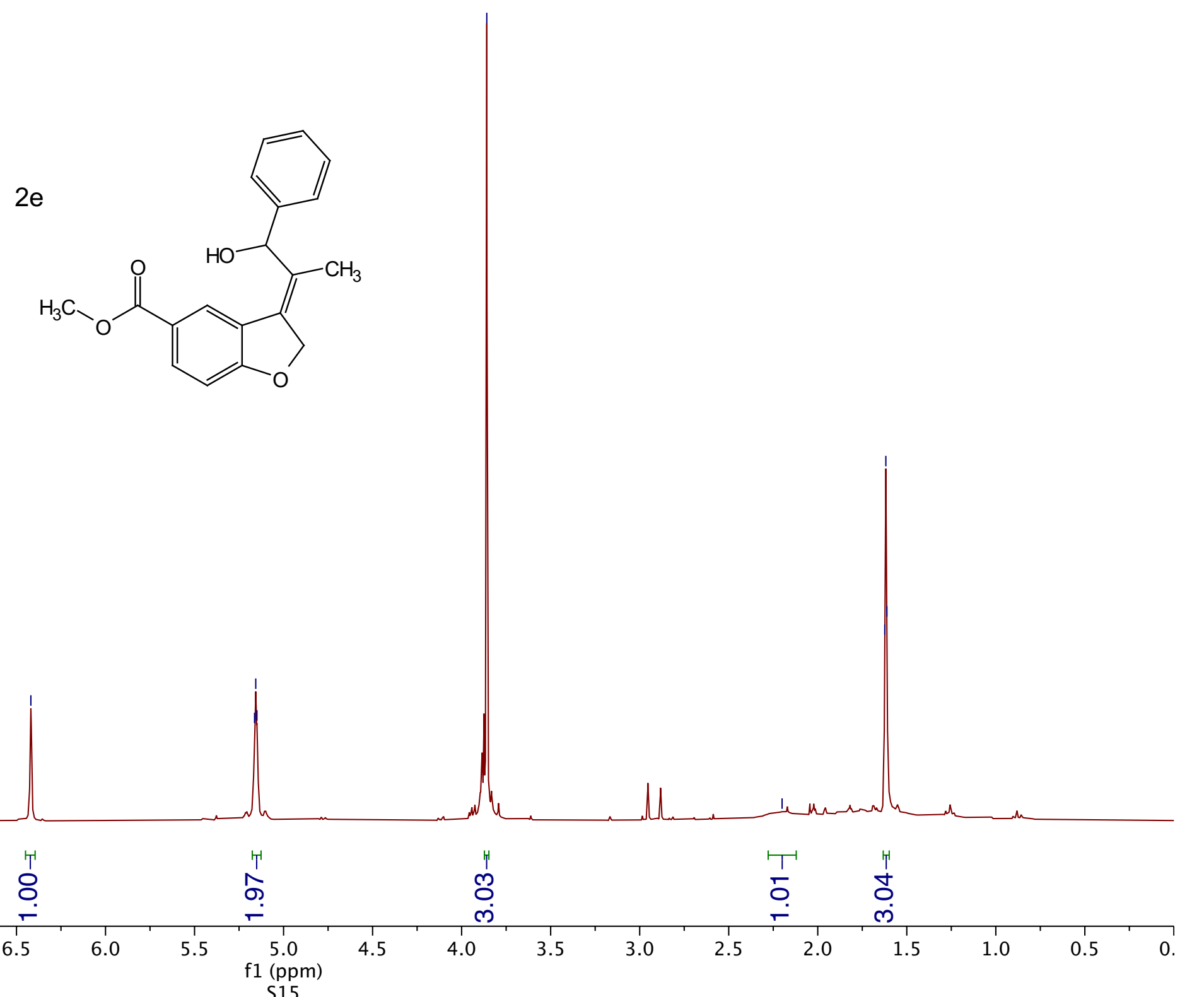




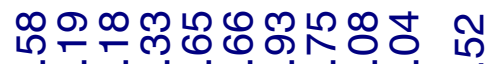

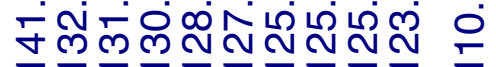

$2 e$<smiles>COC(=O)c1ccc2c(c1)/C(=C(/C)C(O)c1ccccc1)CO2</smiles> 


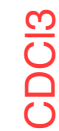

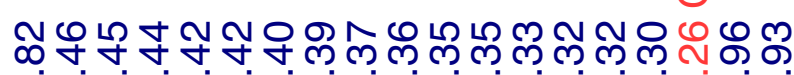

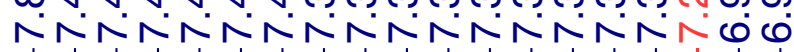

ㄴ,

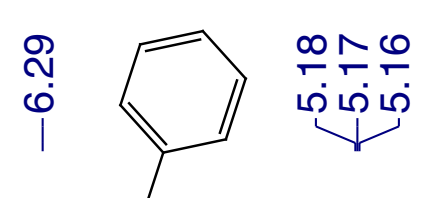

$2 f$

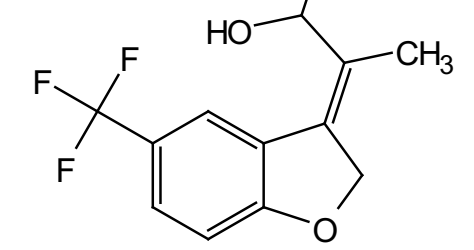

$300 \mathrm{MHz} \quad \mathrm{CDCl}_{3}$

$\infty \sim ⿻ 上$

L
울
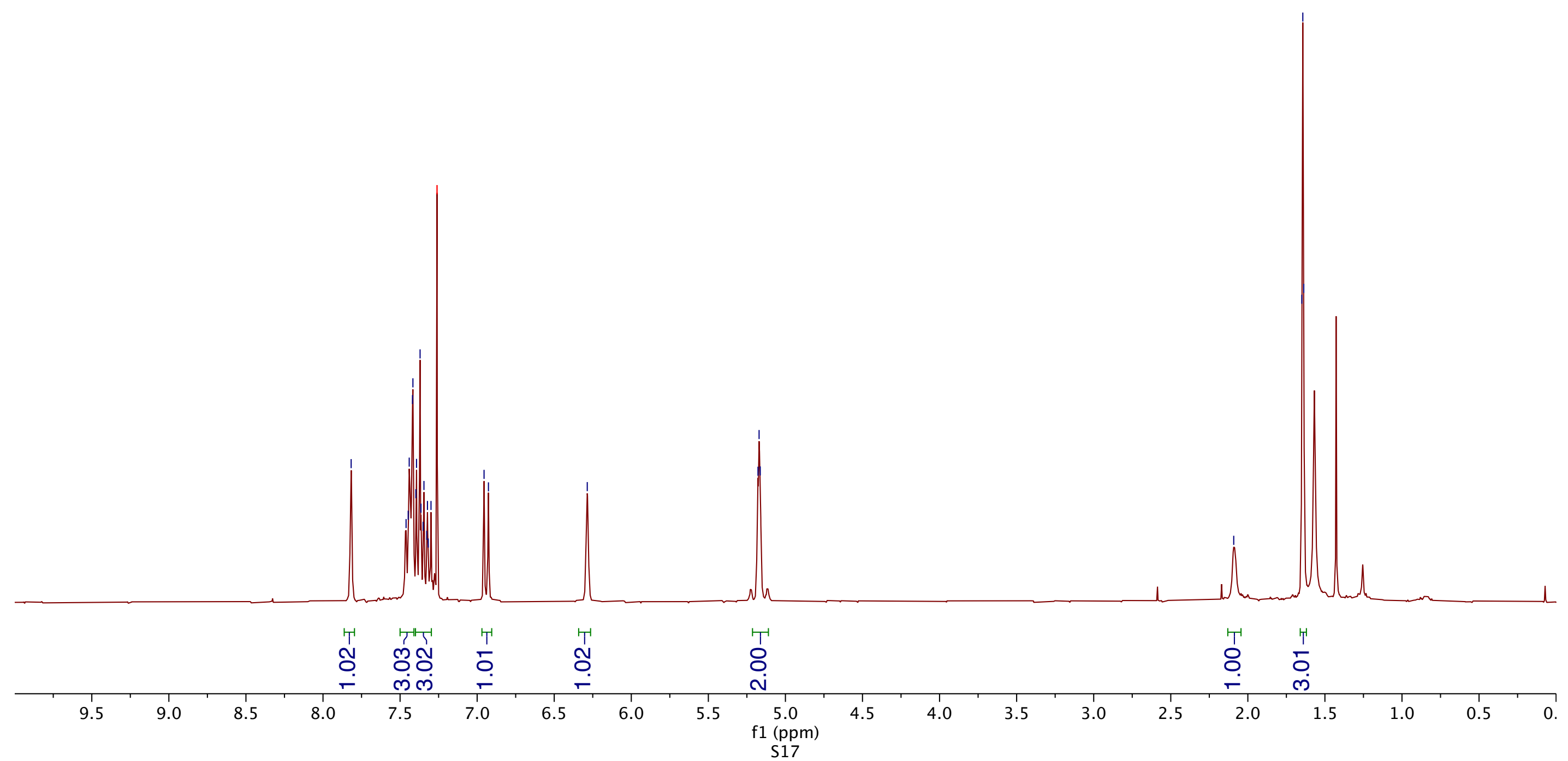

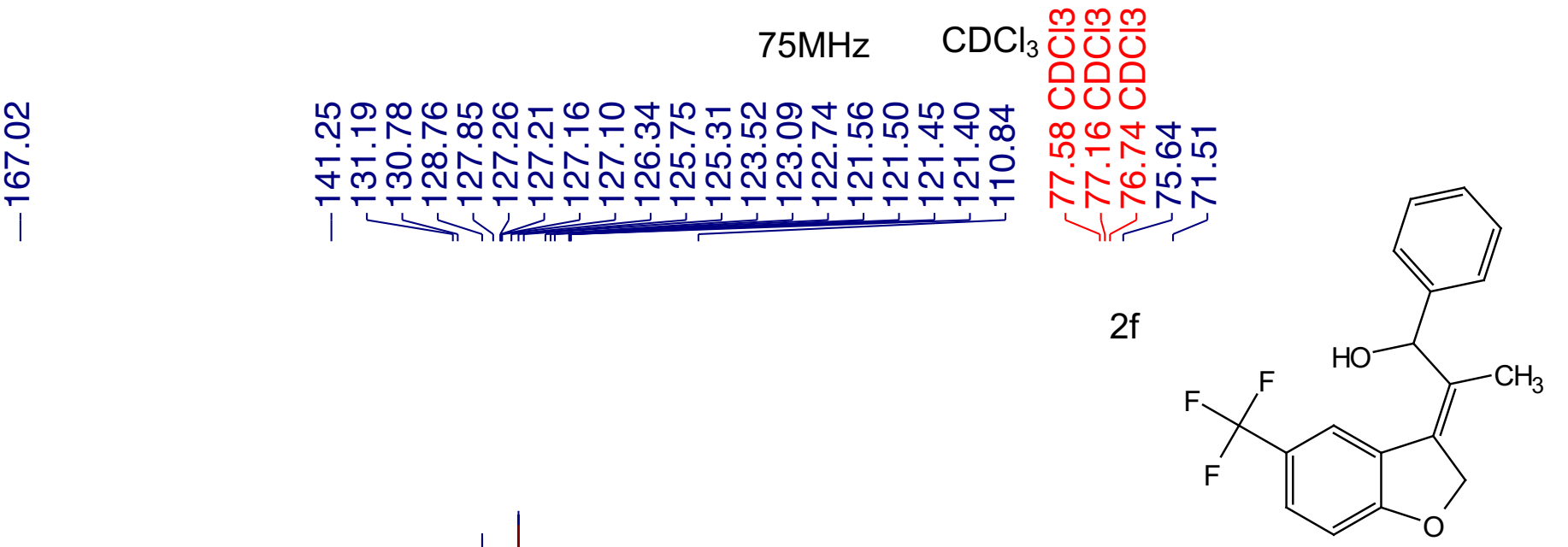

$2 f$
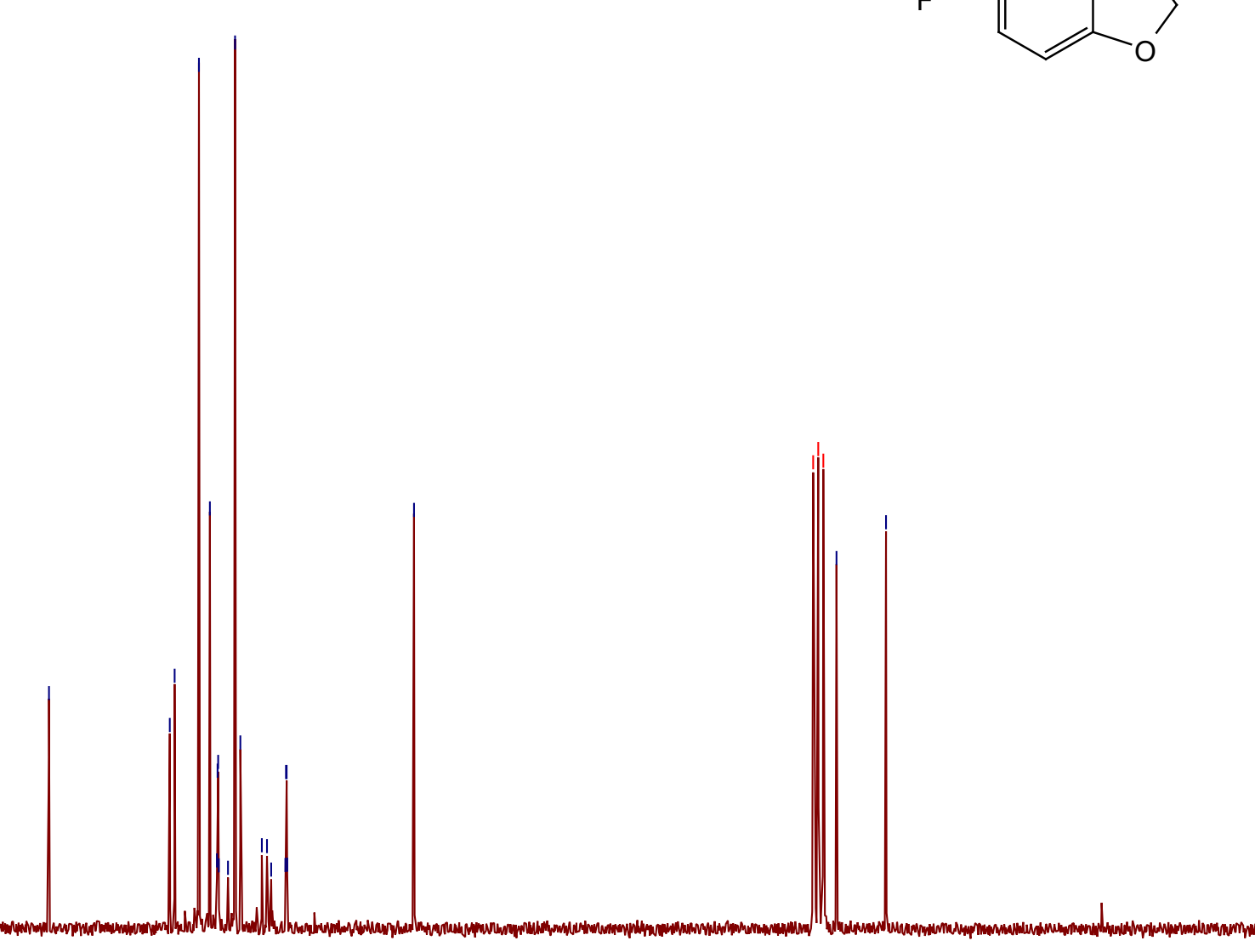


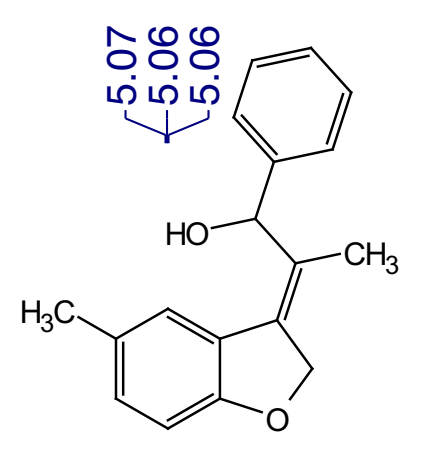

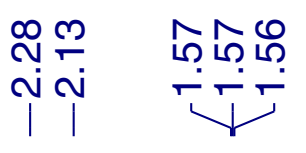
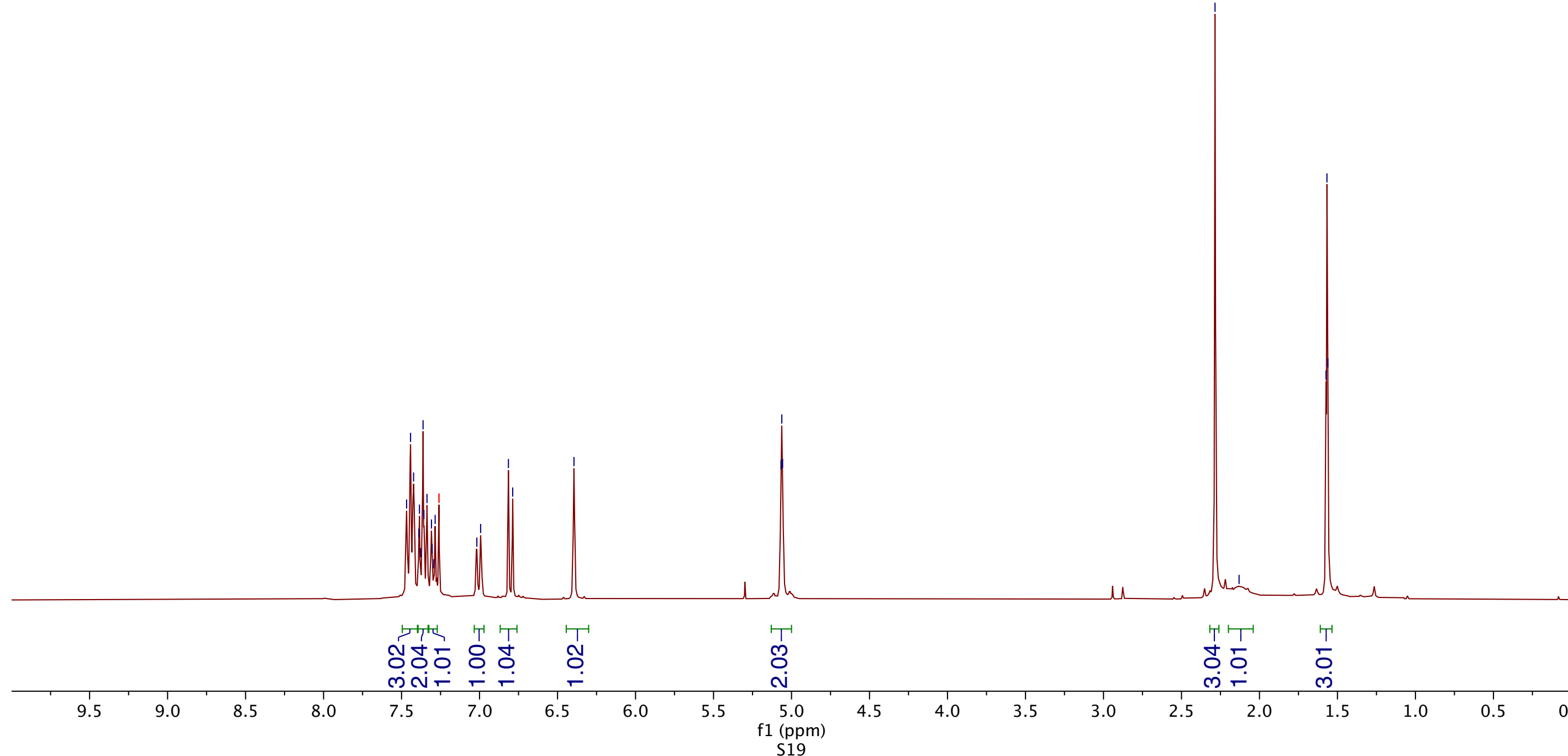
$75 \mathrm{MHz} \quad \mathrm{CDCl}_{3} \frac{m}{\mathrm{U}} \frac{\mathrm{m}}{\mathrm{U}} \frac{\mathrm{m}}{\mathrm{O}}$

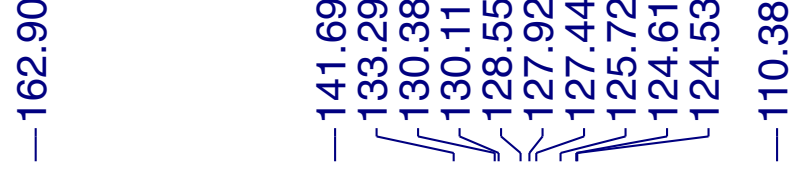

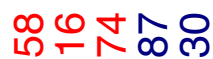

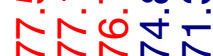

री

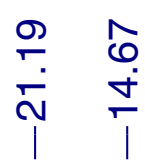

$2 g$
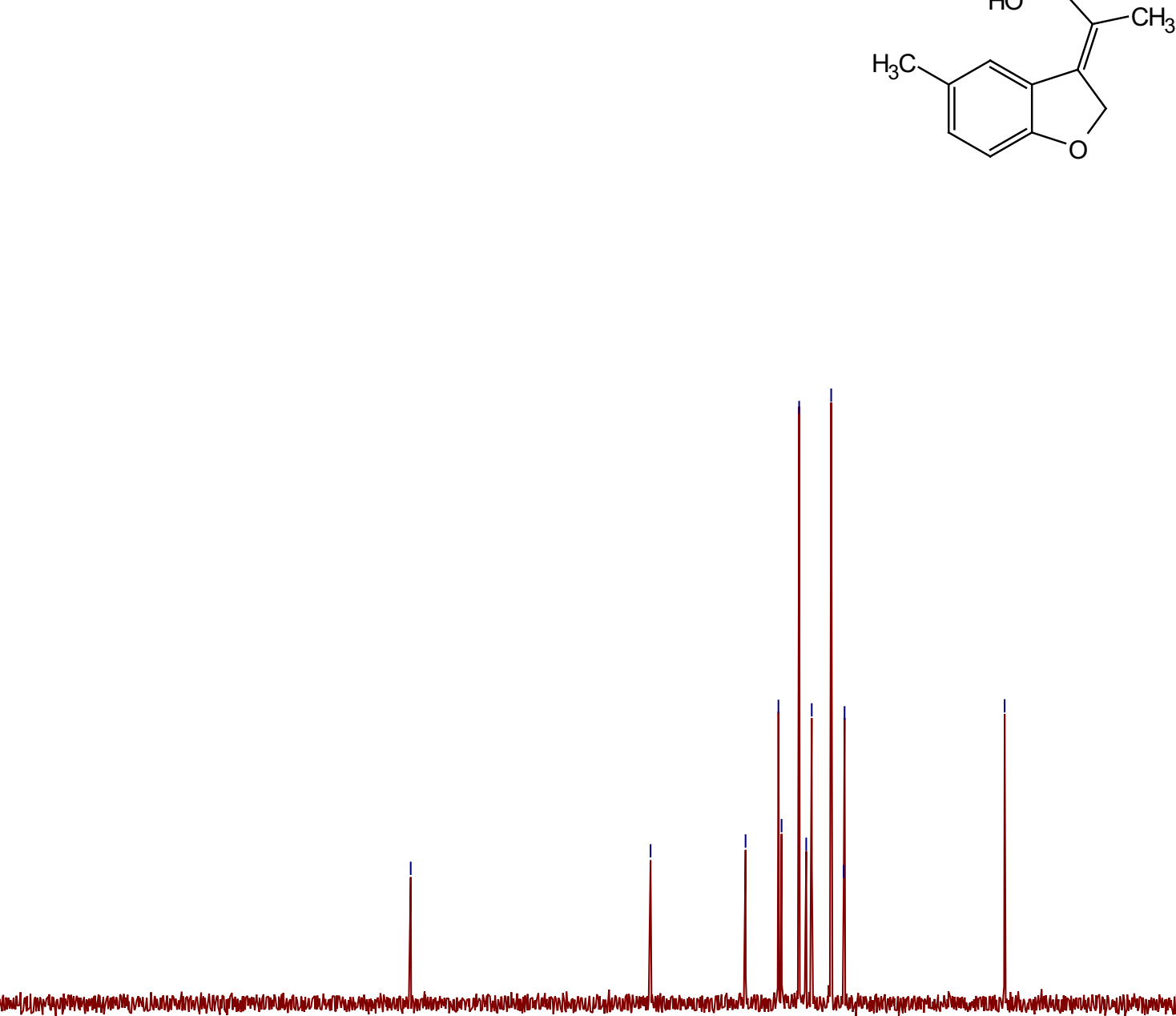

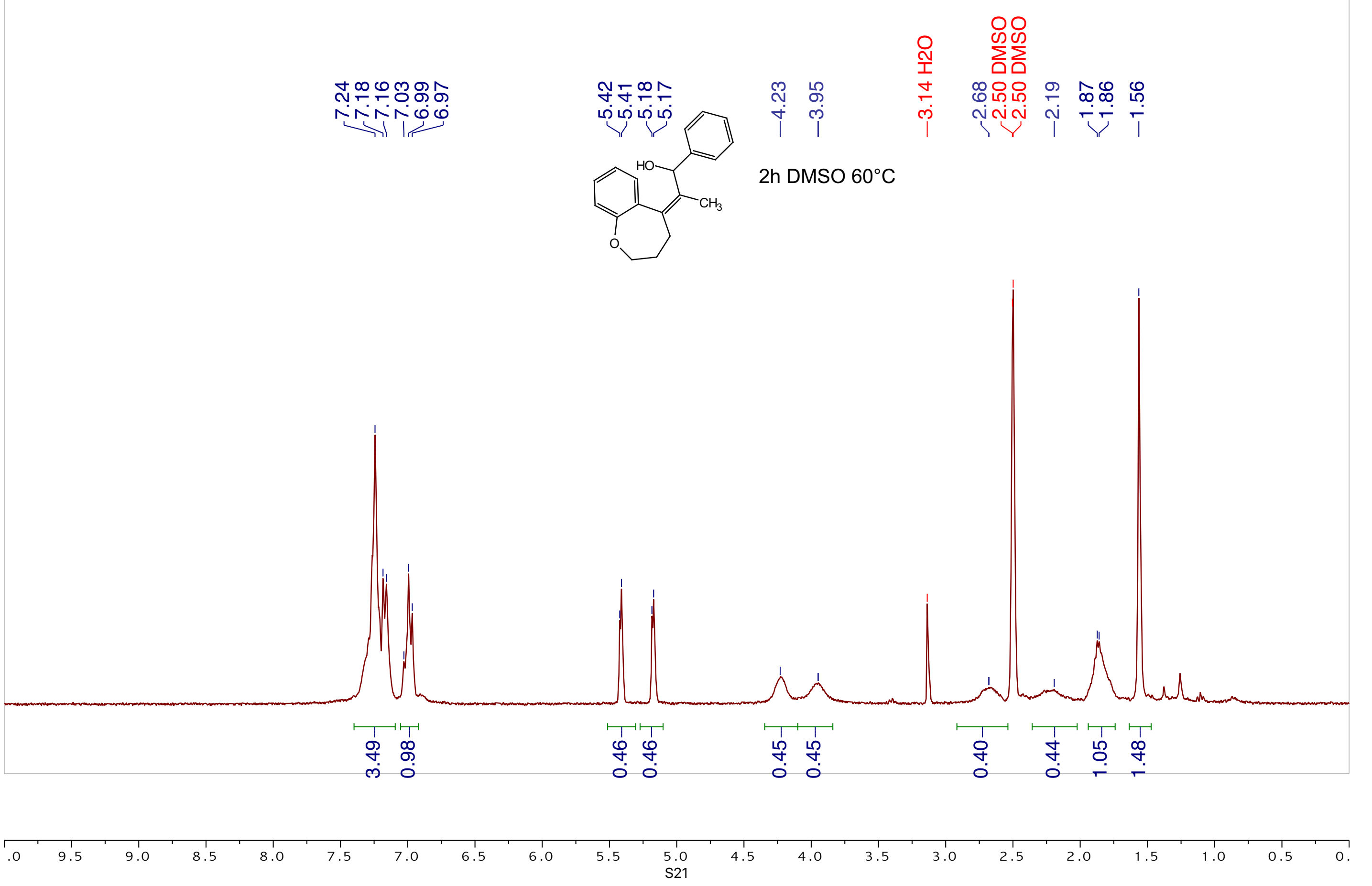

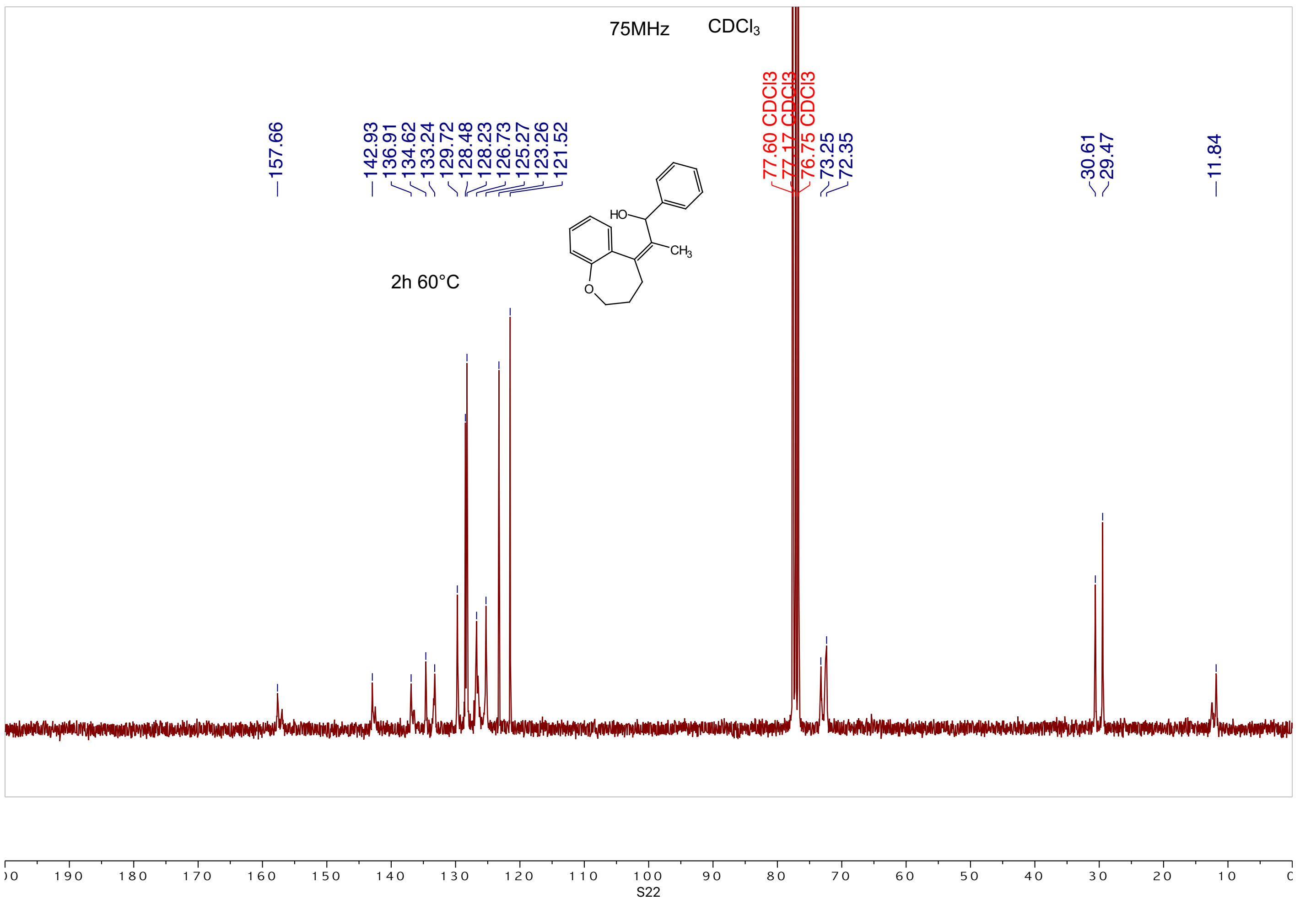
$\frac{m}{0}$

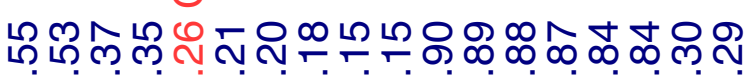

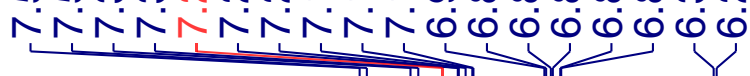

$300 \mathrm{MHz} \quad \mathrm{CDCl}_{3}$

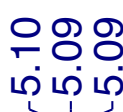

$\infty$

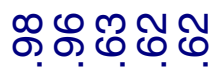

m

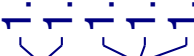

एँ<smiles>COc1ccc(C(O)/C(C)=C2/COc3ccccc32)cc1</smiles>

$4 a$

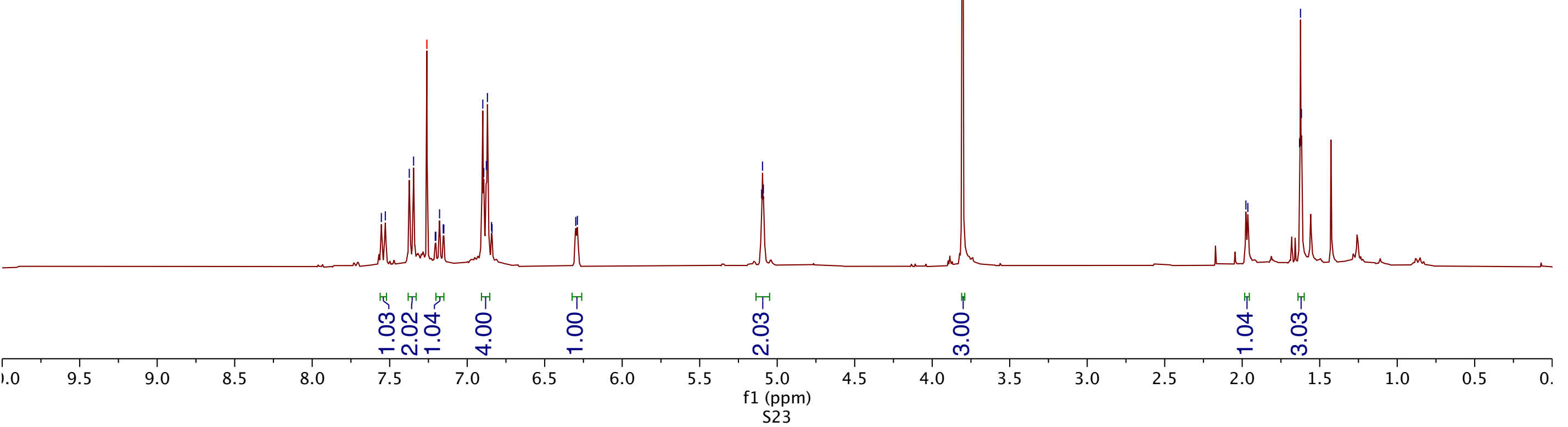




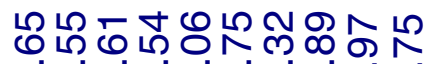

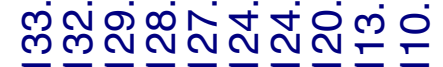

可应

\section{ปูง}

$\infty 04-$

ヘペ包去

ल)

Niñ

เก

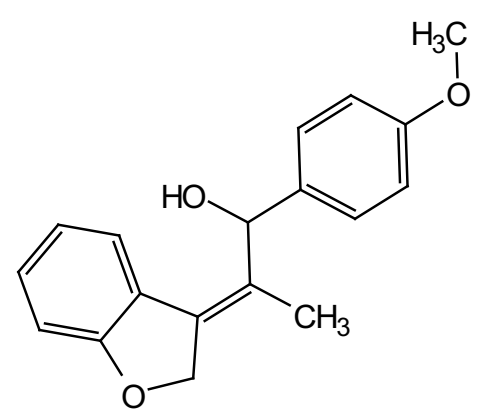

$4 a$

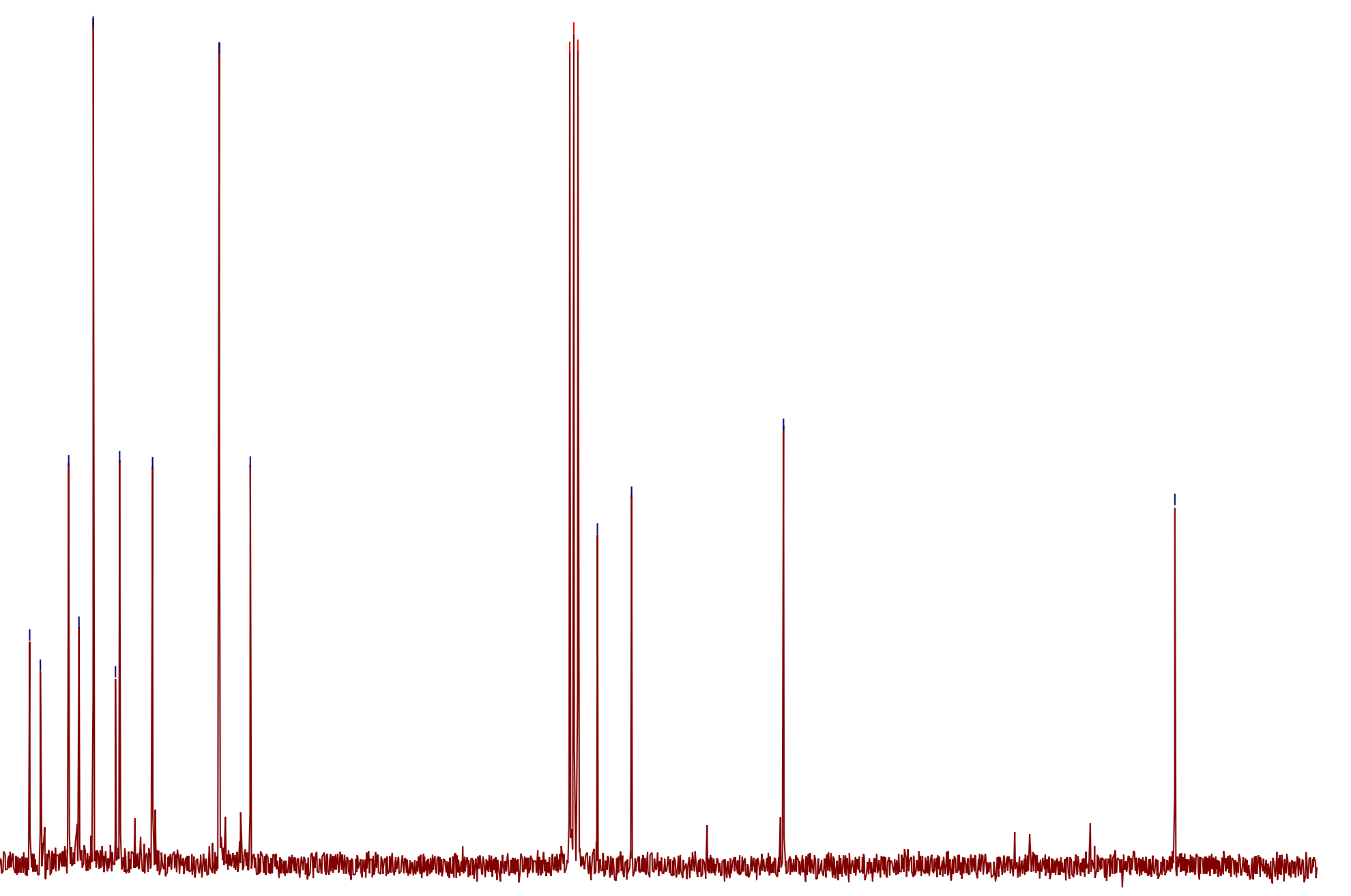




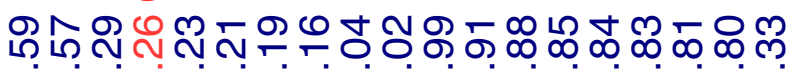

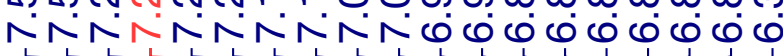<smiles>COc1cccc(C(O)C(C)=C2COc3ccccc32)c1</smiles>

$\stackrel{\substack{0 \\ i}}{i}$

$\frac{1}{1}$ 
$75 \mathrm{MHz} \quad \mathrm{CDCl}_{3} \frac{\mathrm{m}}{\mathrm{O}} \frac{\mathrm{m}}{\mathrm{O}} \frac{\mathrm{m}}{\mathrm{O}}$

๓

莳

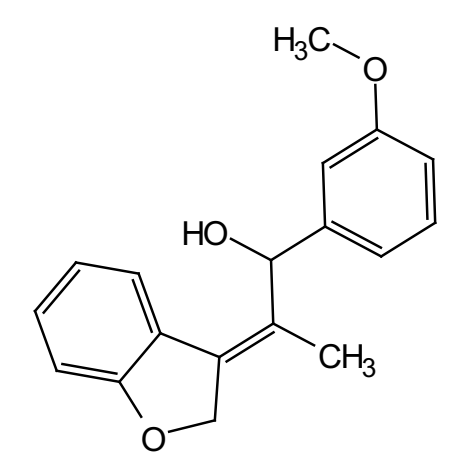

$4 b$

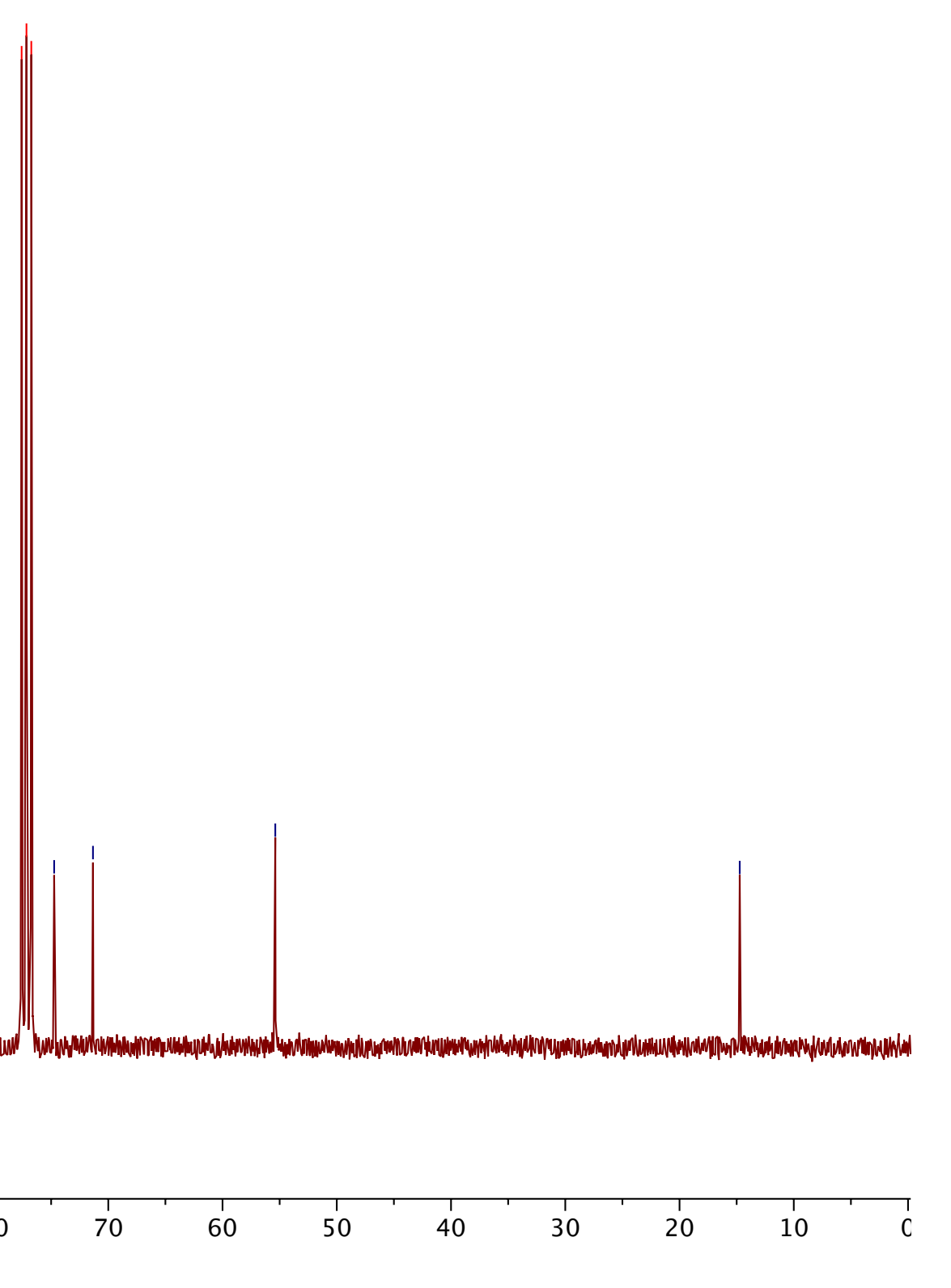




ำ
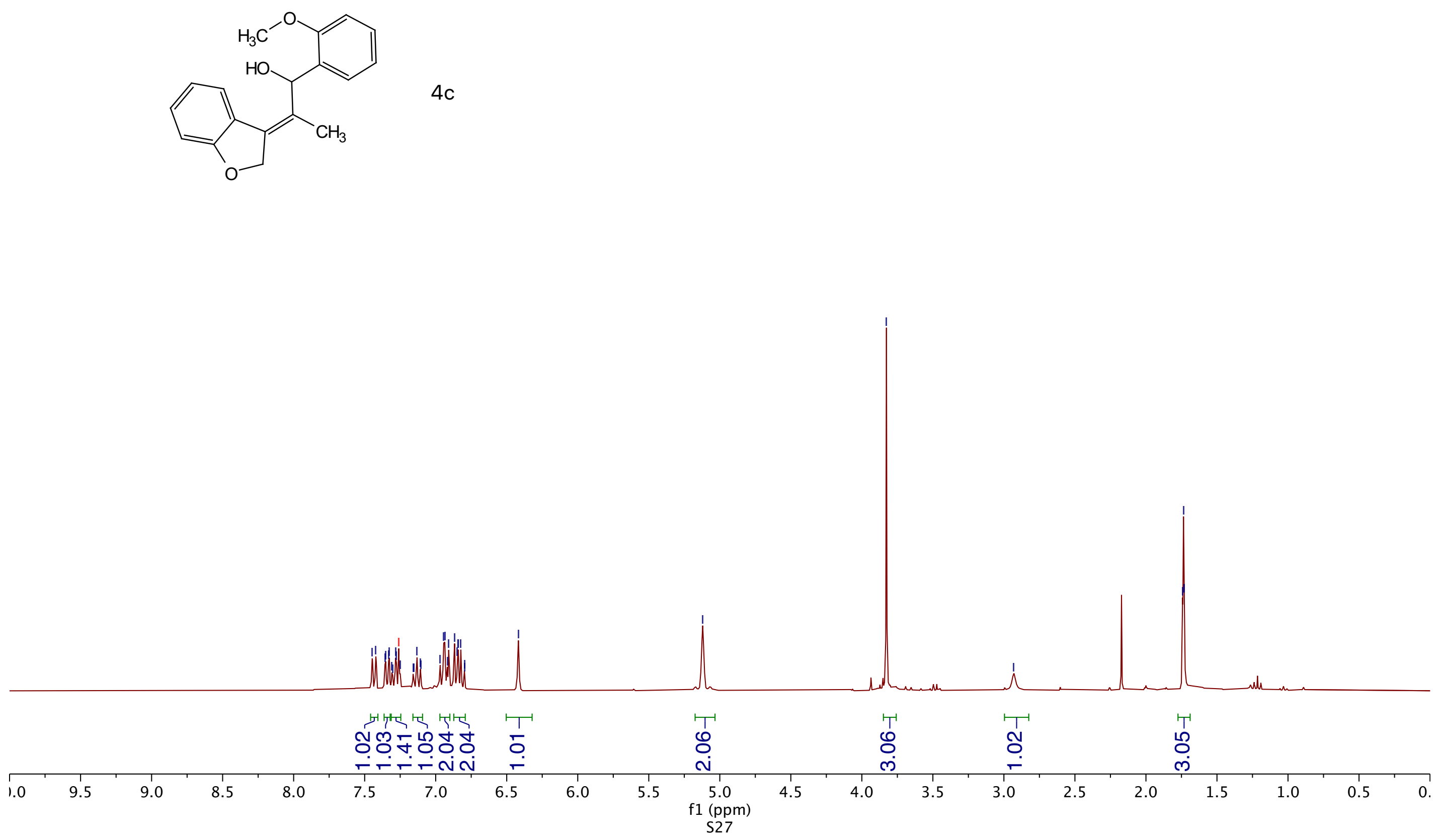

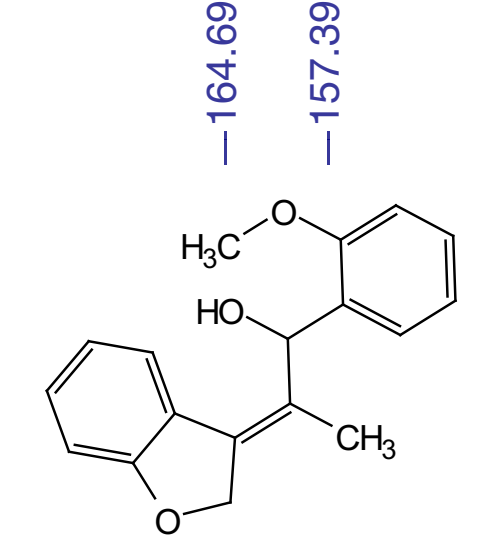

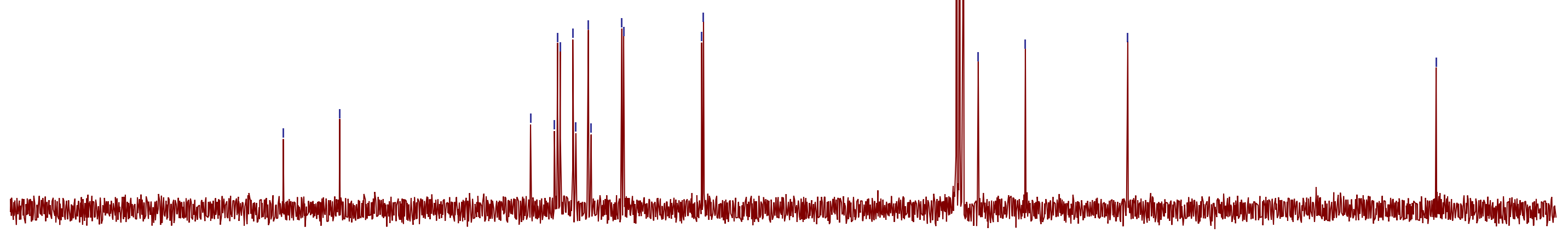


ம

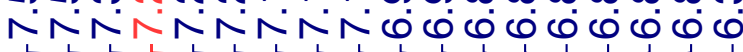

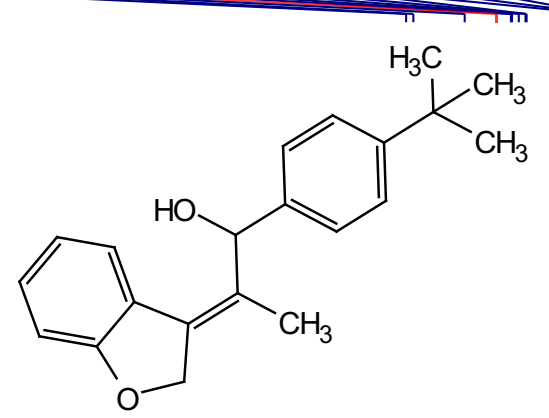

$4 d$
으용용

ما

r
政

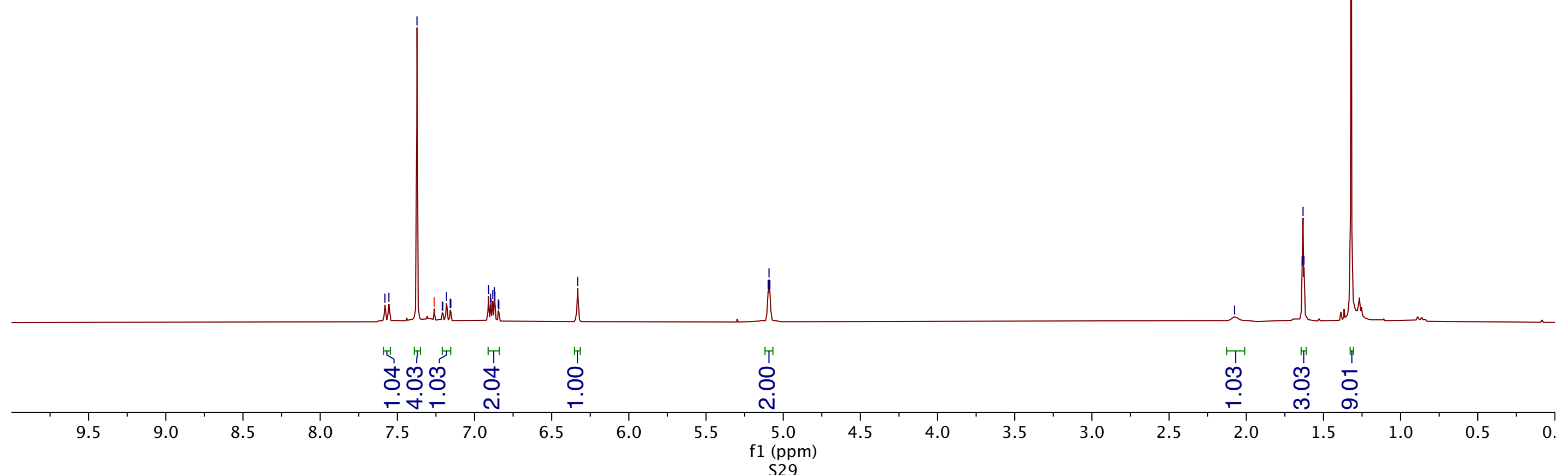




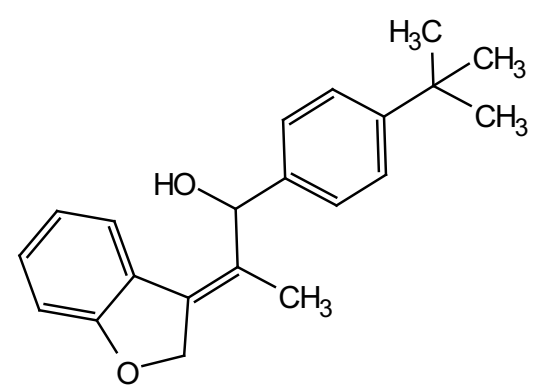

$4 d$

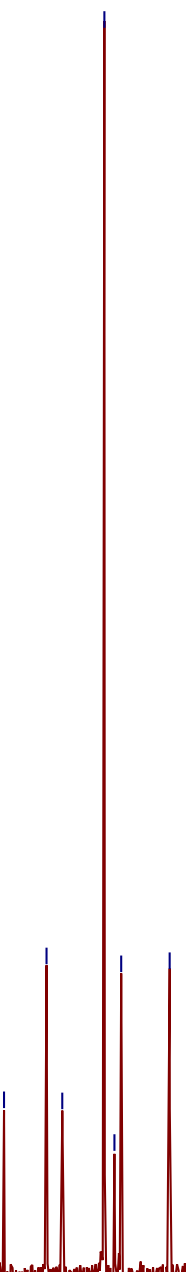




\section{으용}

เค่

r

|

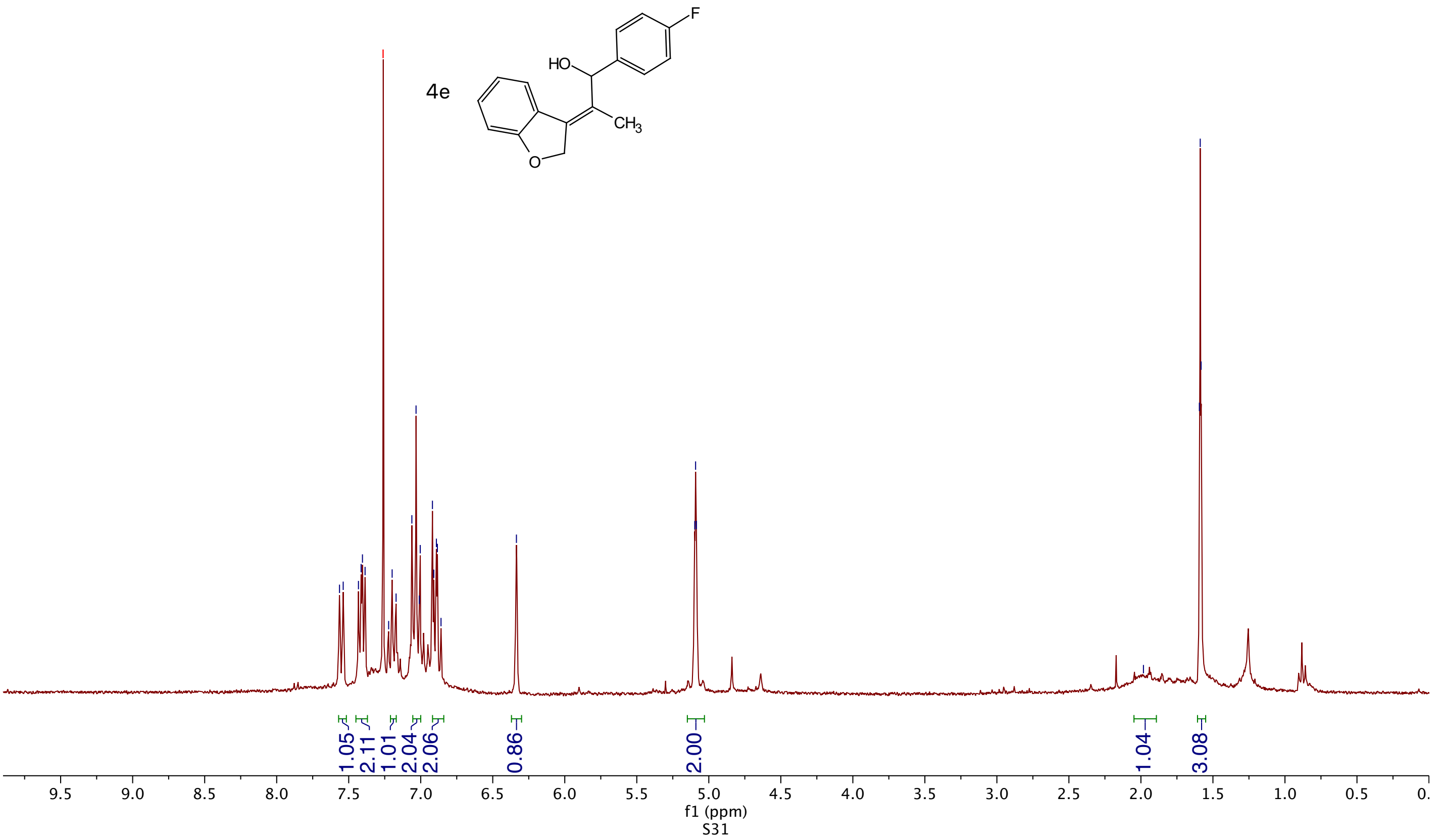




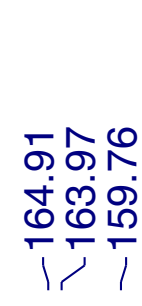

$75 \mathrm{MHz}$

$\mathrm{CDCl}_{3}$

ஸุฒ

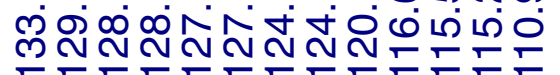
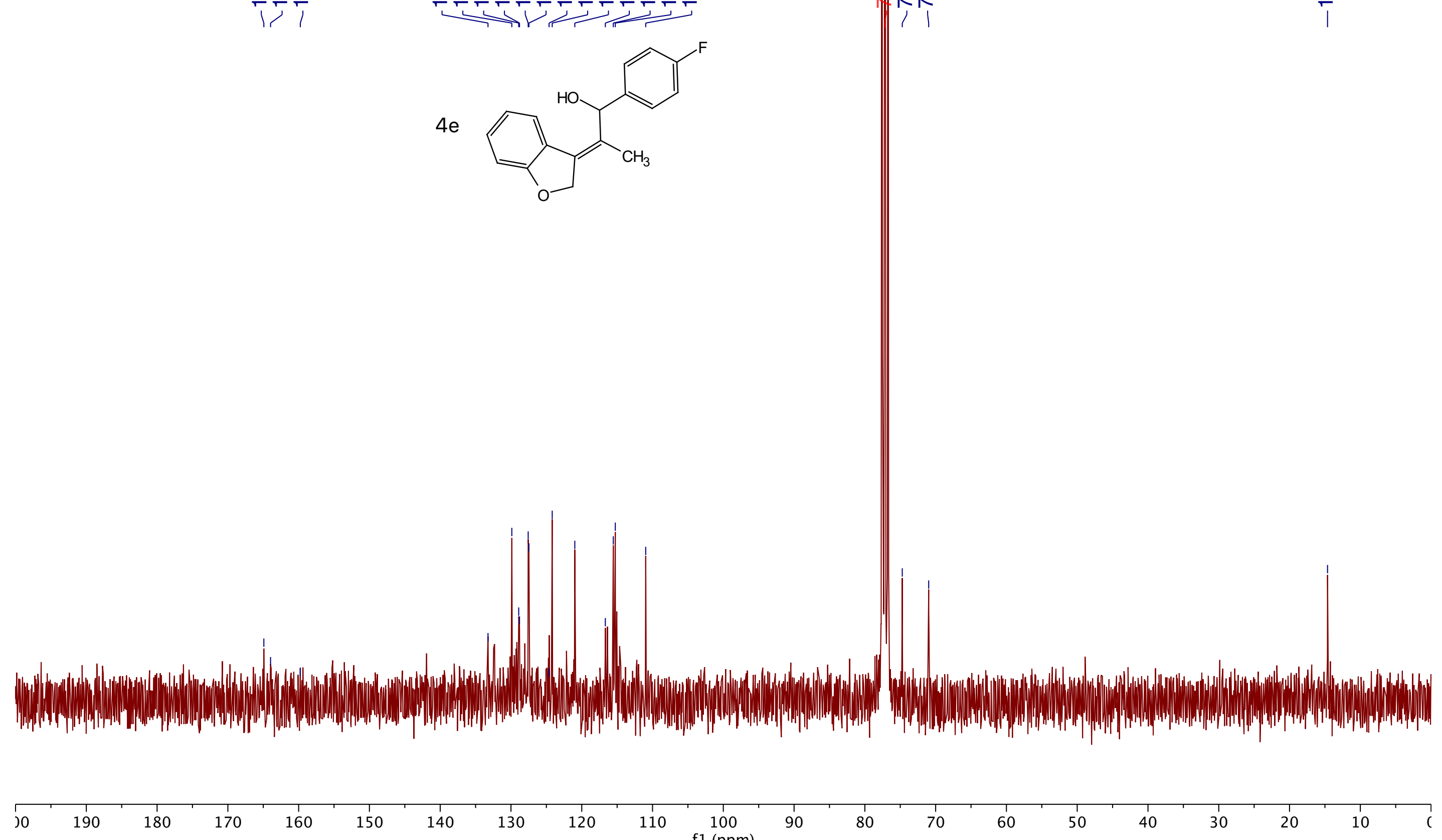

190

180

170

160

150

140

130

120

110

100

90

80

70

60

50

40

30

20

10 

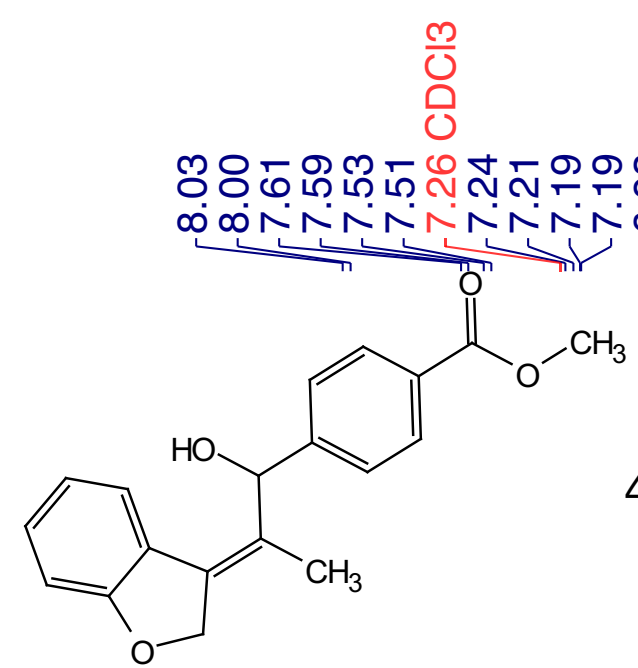

$300 \mathrm{MHz} \quad \mathrm{CDCl}_{3}$

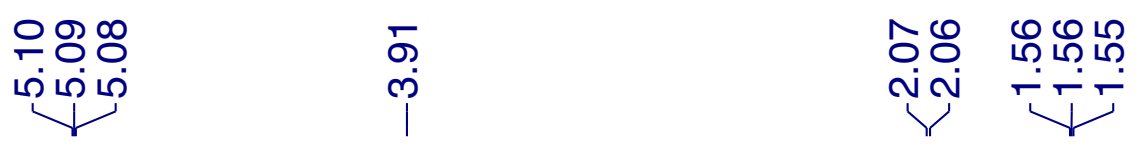

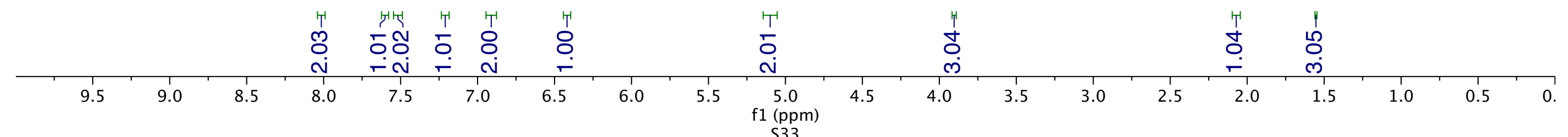


$\pm \hat{\infty}$

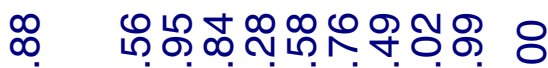

ஸิษั่

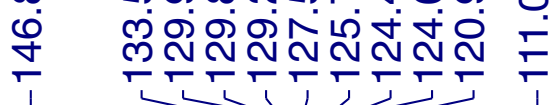

000

œ

iñ

กิ

nNin

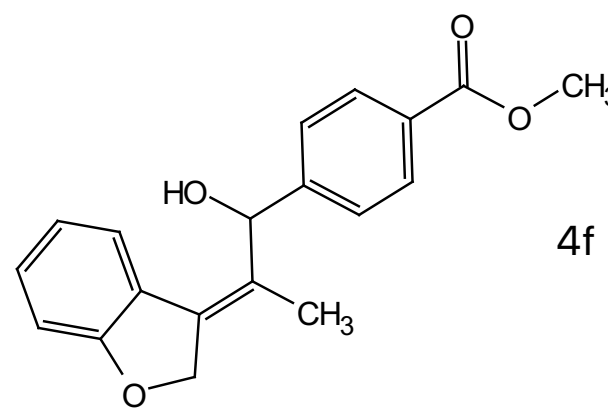

$4 f$

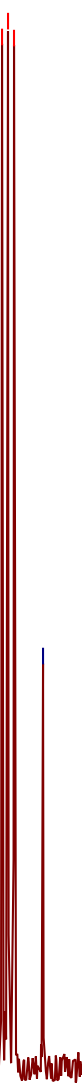

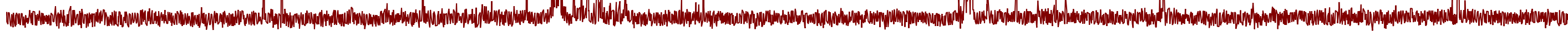

180

170

160

150

140

130

120

110

100
$1(\mathrm{ppm})$

90

80

70

60

50

40

30

20

10 
$\frac{m}{0}$

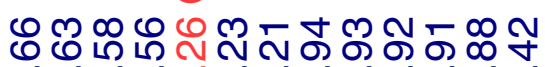

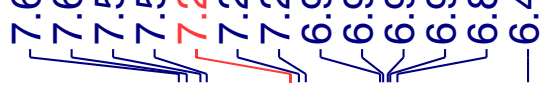

$300 \mathrm{MHz} \quad \mathrm{CDCl}_{3}$

운

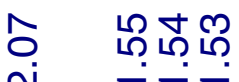

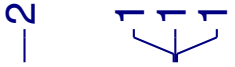

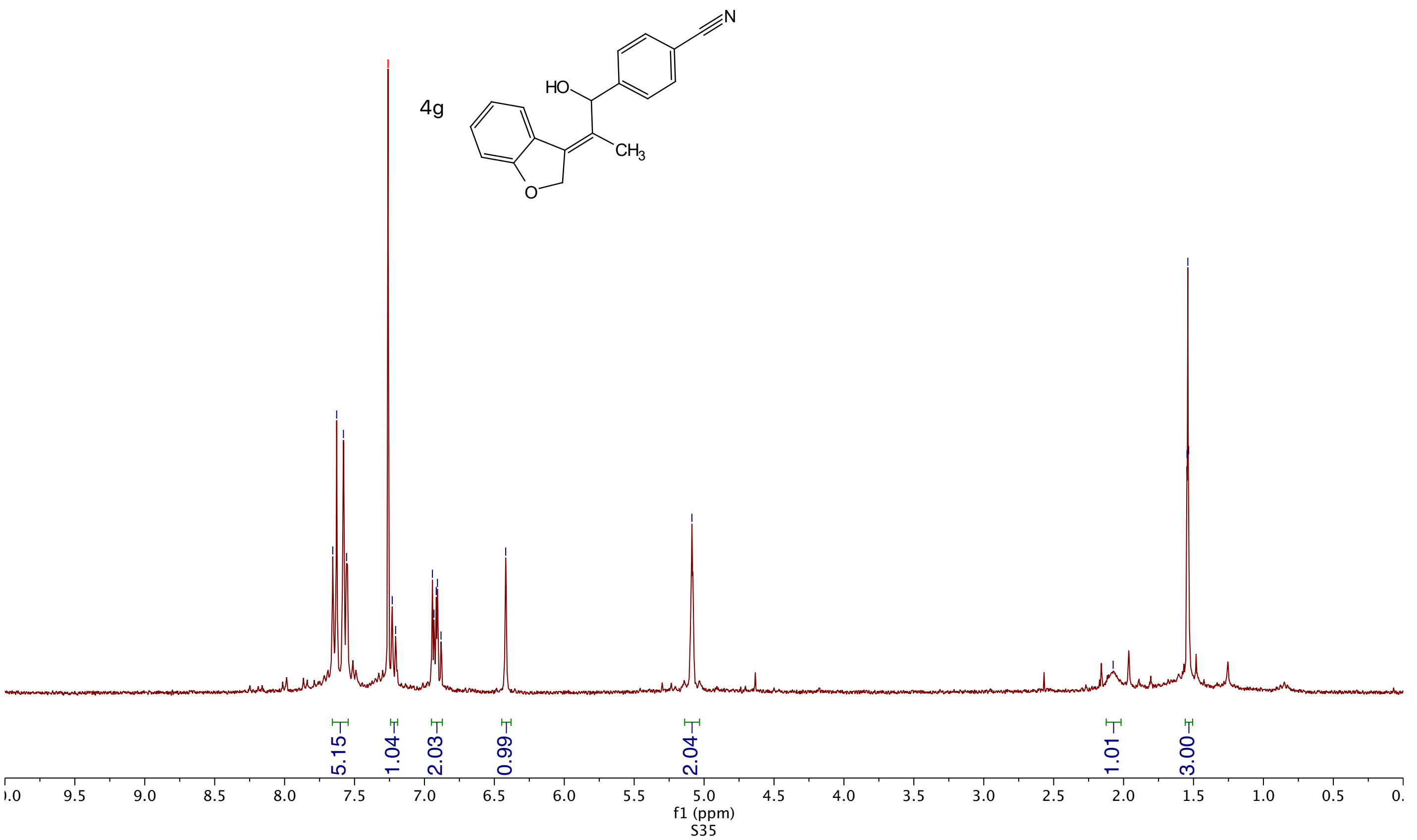



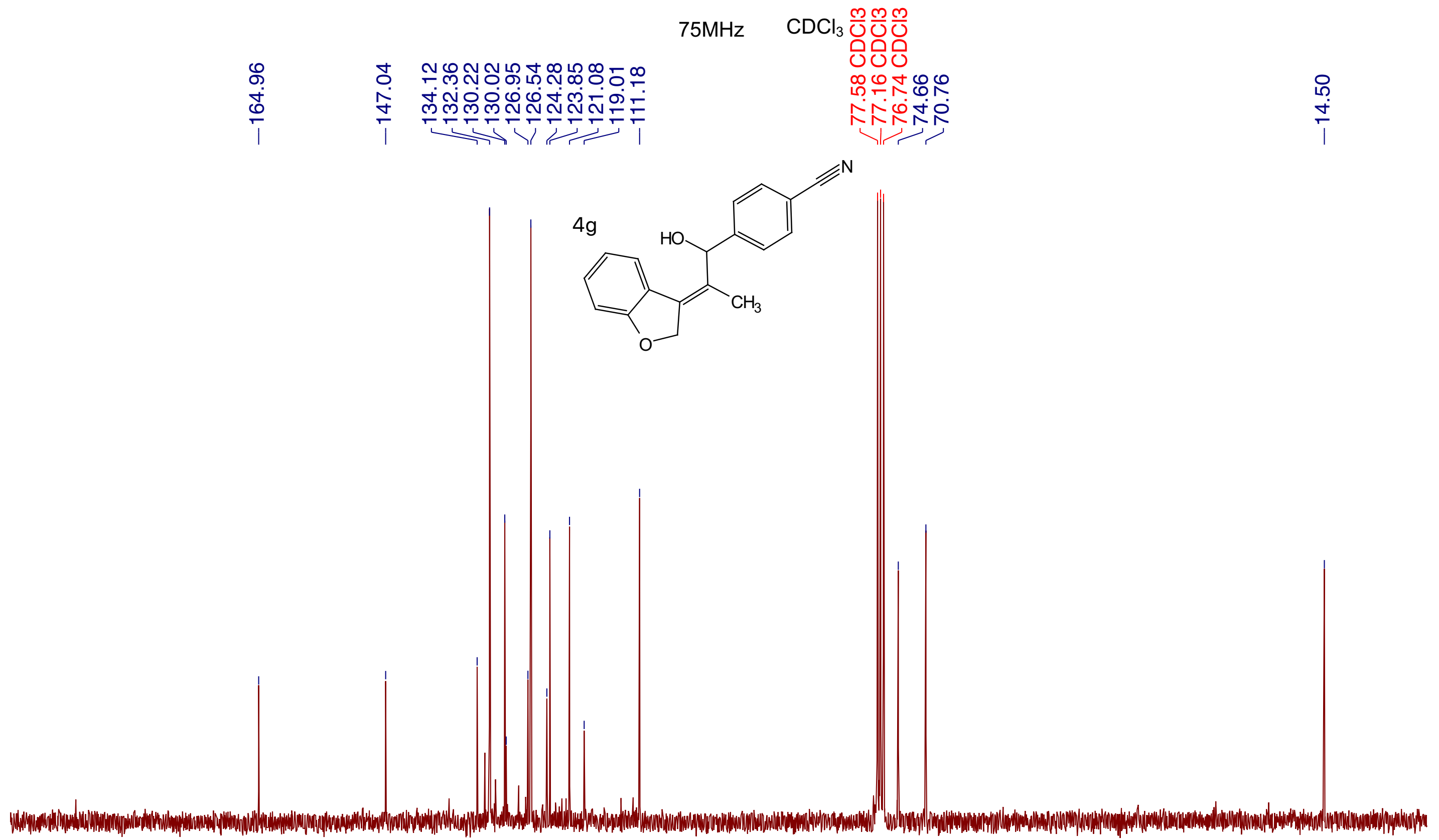
鱼

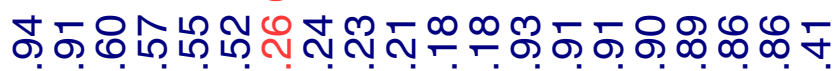

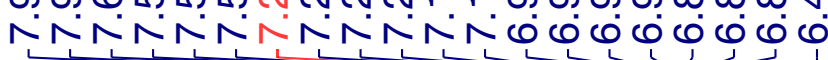

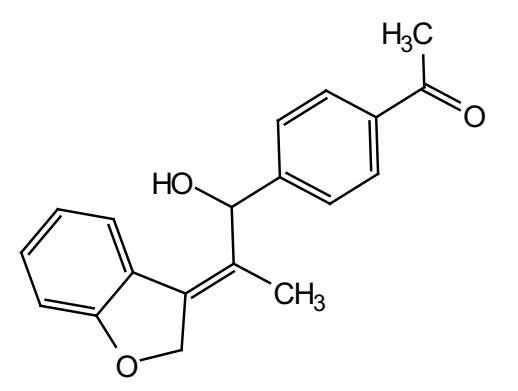

\section{$300 \mathrm{MHz} \quad \mathrm{CDCl}_{3}$}

กิธิ์

ن

$4 \mathrm{~h}$

ำ
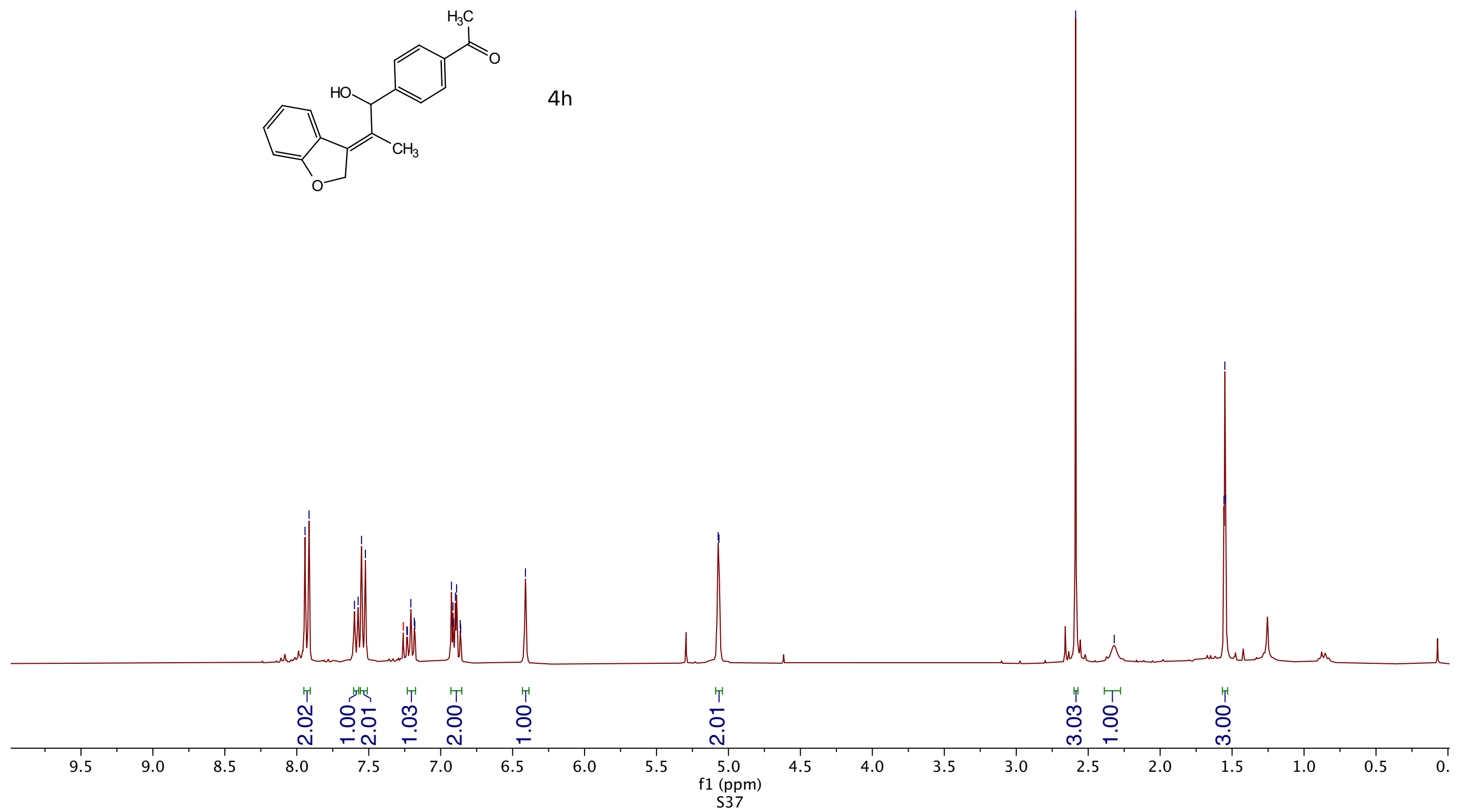
$75 \mathrm{MHz} \quad \mathrm{CDCl}_{3} \quad \frac{m}{\mathrm{v}} \frac{m}{\mathrm{v}}$

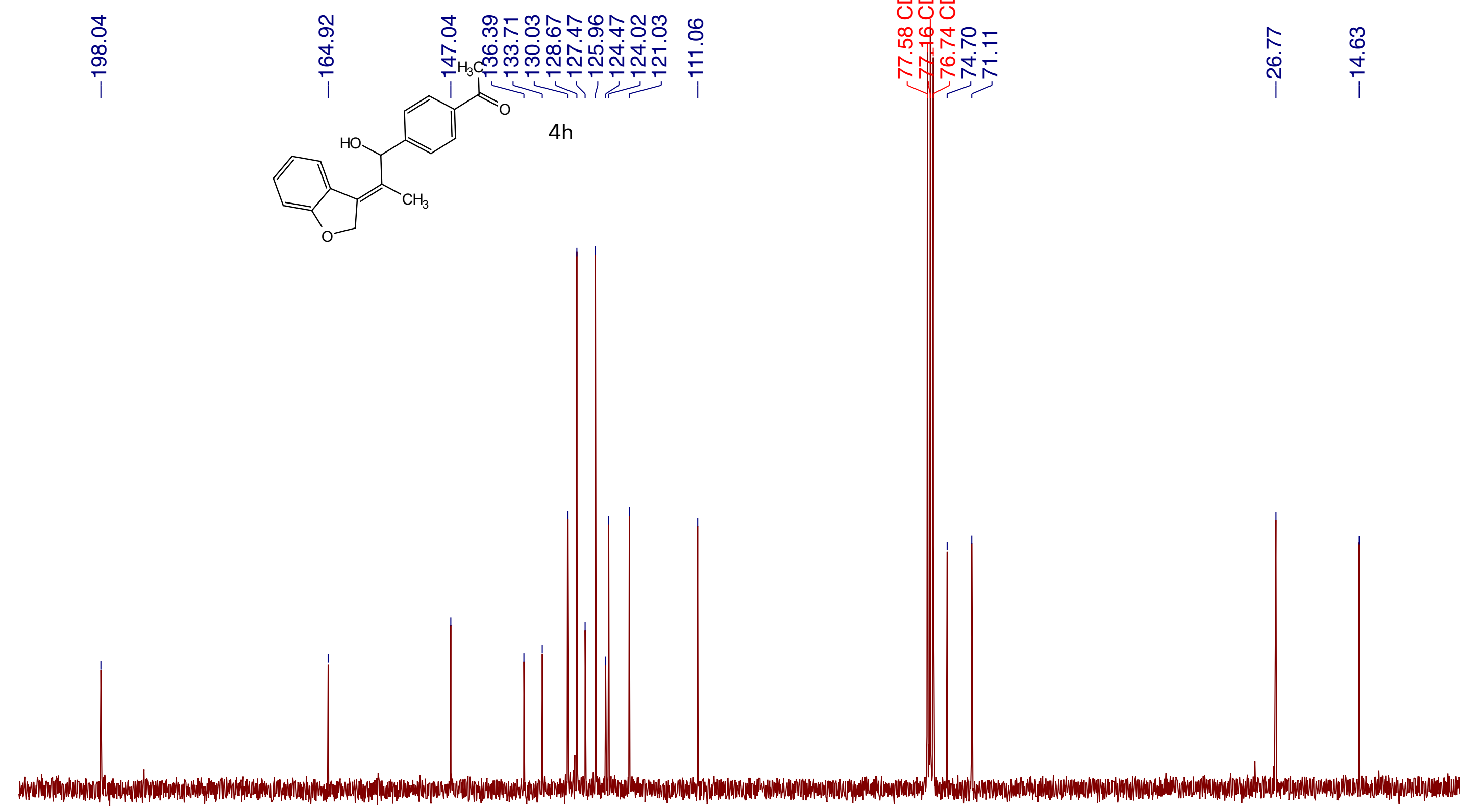




\section{号}

め

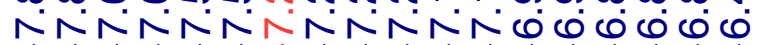

$\underbrace{1}$

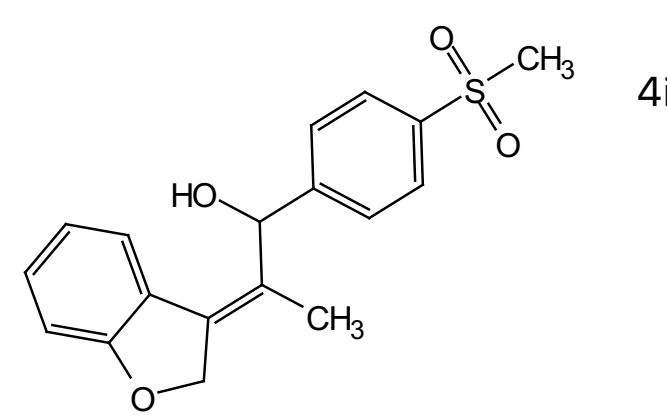

$4 i$
$300 \mathrm{MHz} \quad \mathrm{CDCl}_{3}$

융

เค่

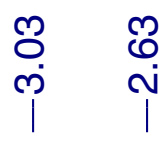

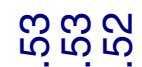

r菏

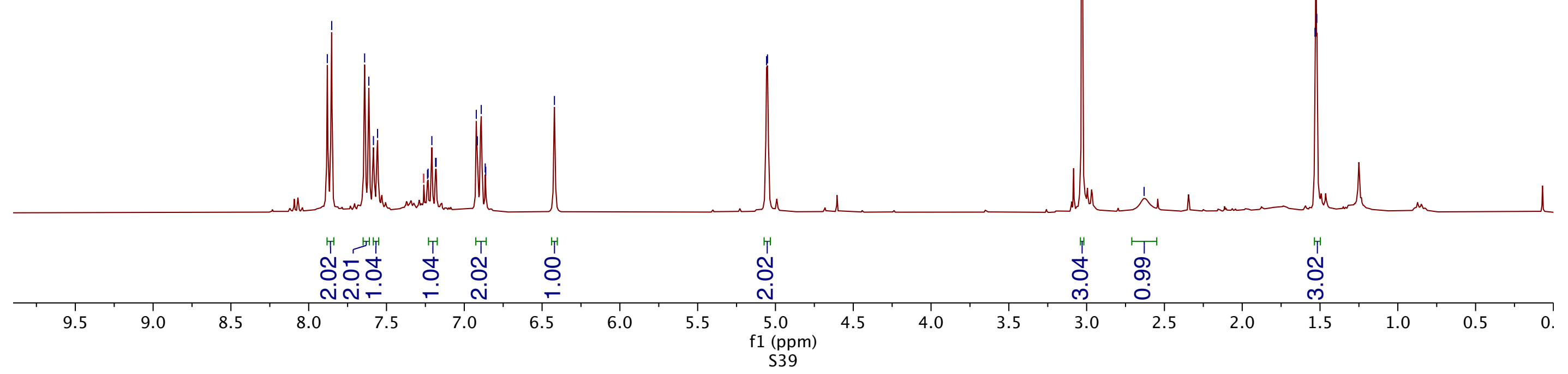


$75 \mathrm{MHz} \quad \mathrm{CDCl}_{3} \frac{\mathrm{m}}{\mathrm{v}} \frac{\mathrm{m}}{\mathrm{U}} \frac{\mathrm{m}}{\mathrm{O}}$

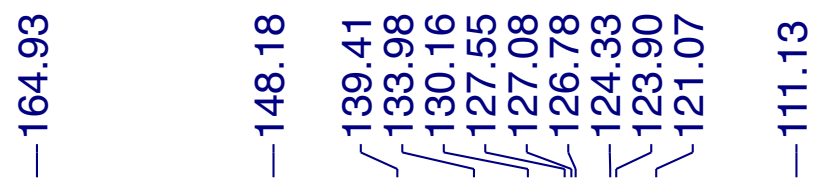<smiles>C/C(=C1/COc2ccccc21)C(O)c1ccc(S(C)(=O)=O)cc1</smiles>

$4 i$
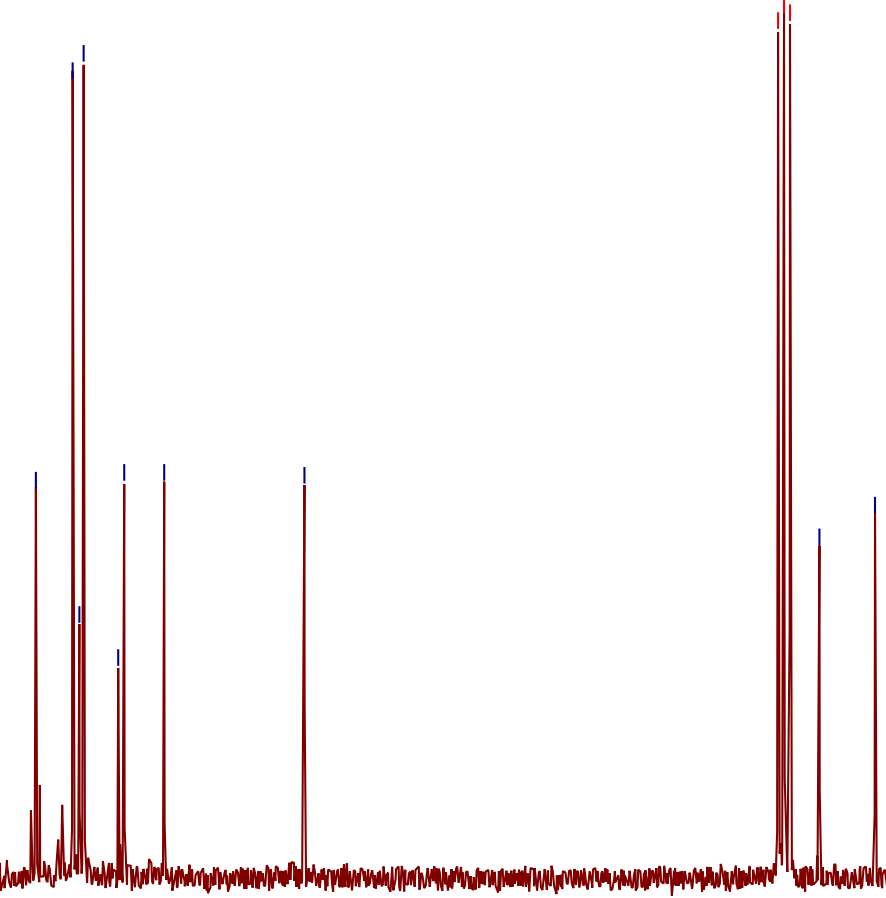


\section{品}

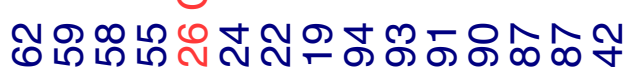

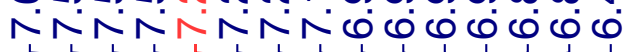

m m

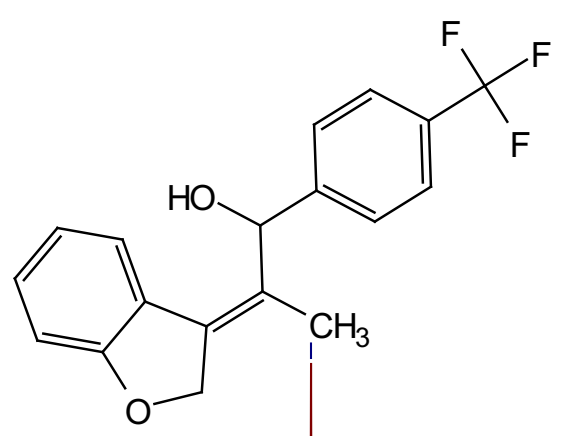

4j
$300 \mathrm{MHz} \quad \mathrm{CDCl}_{3}$

용

เค่

Y

ㄱ.
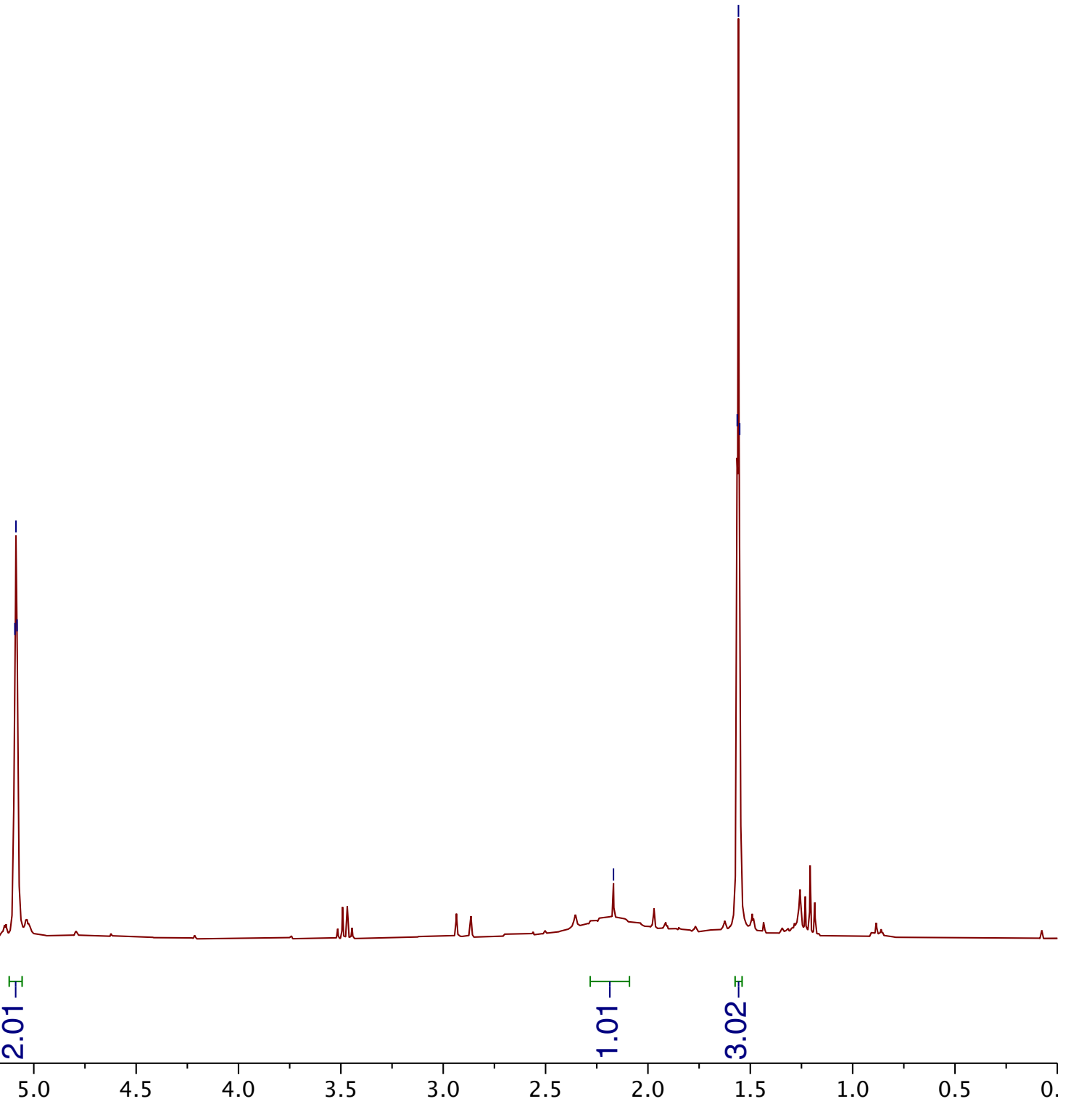

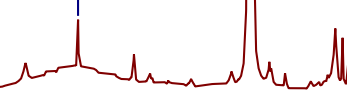

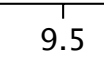

8.5
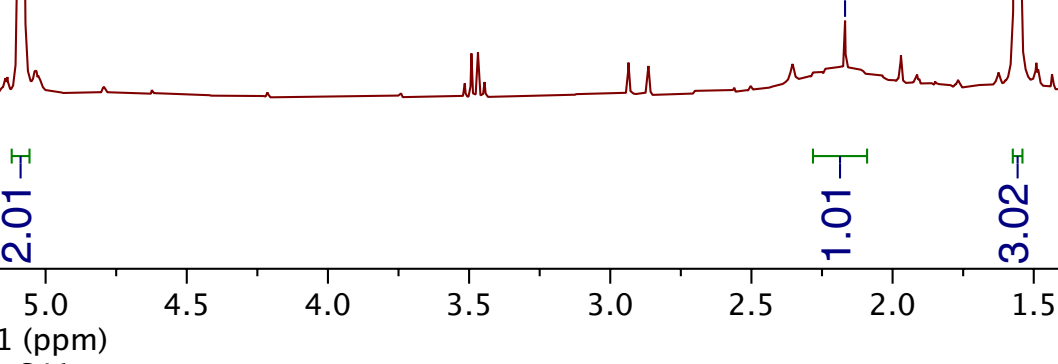

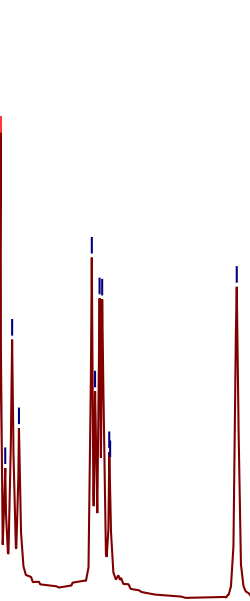




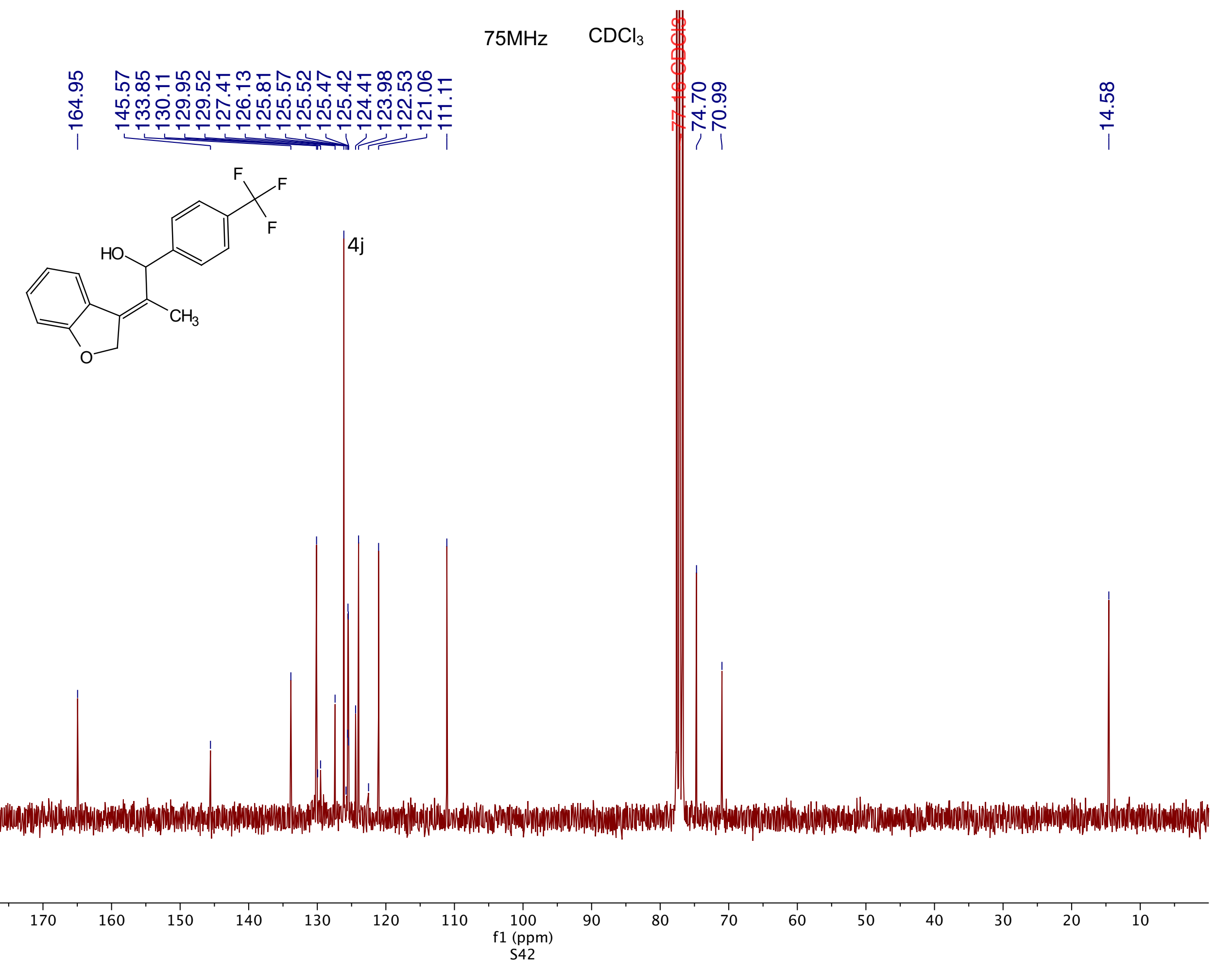


鱼

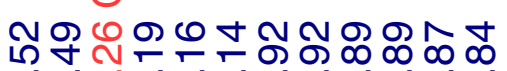

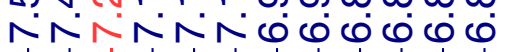

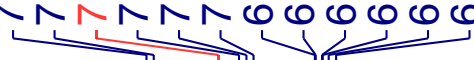

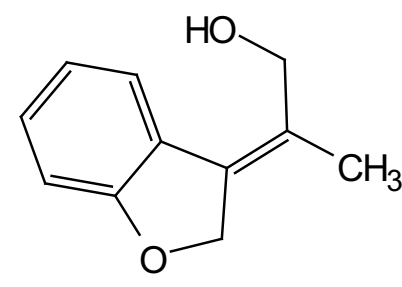

$300 \mathrm{MHz} \quad \mathrm{CDCl}_{3}$

வூ

ॠ

-

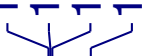

$4 k$

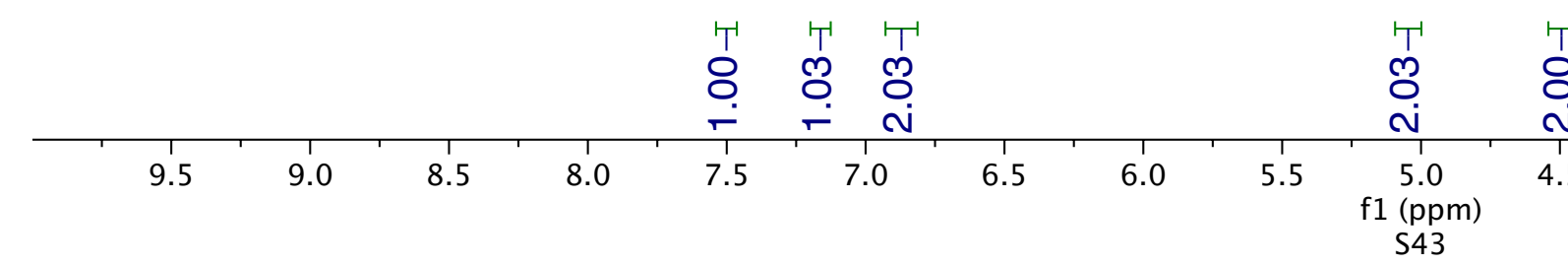

ธุด

लं०

mo 


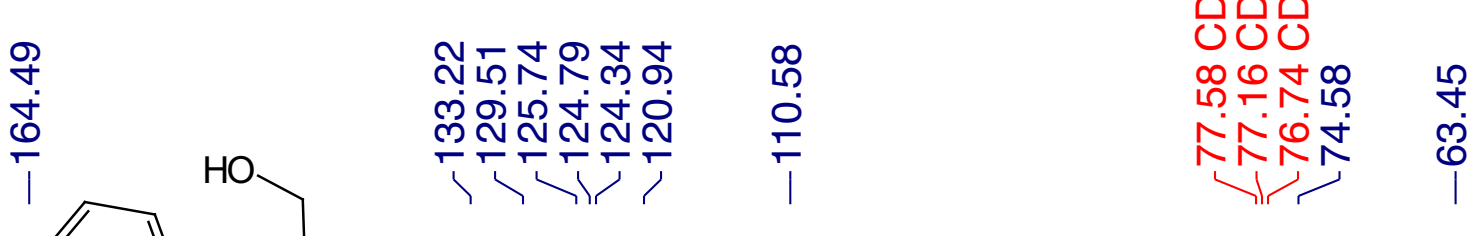

$4 k$ 


\section{는든응

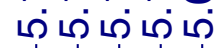

ఫ

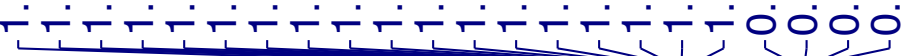

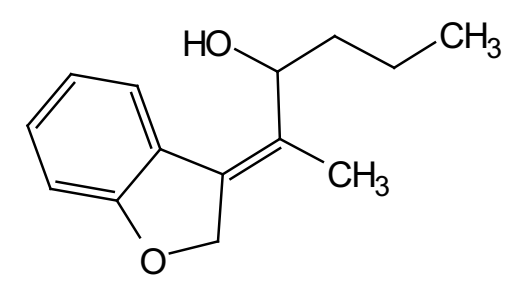

41
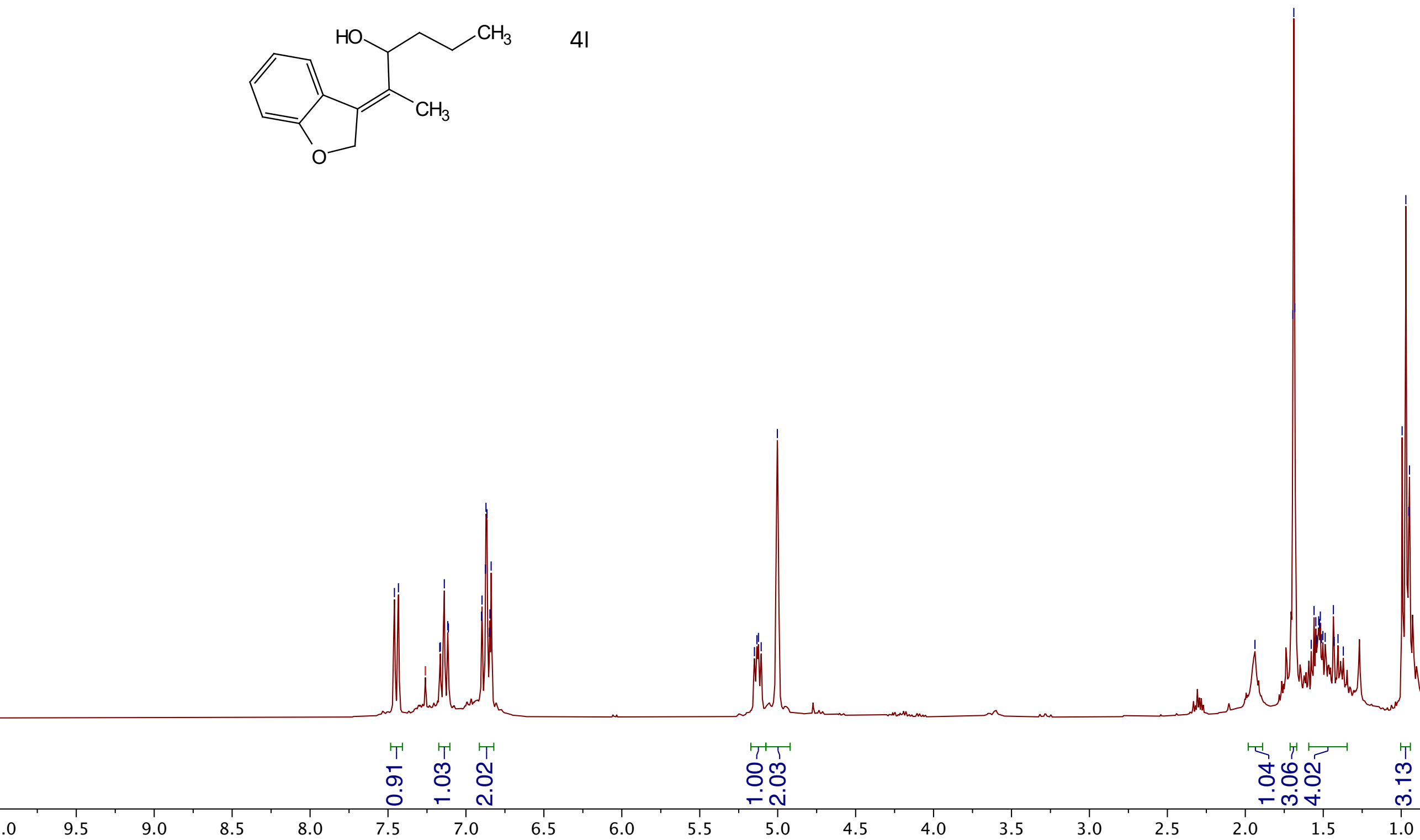

雚

6.0

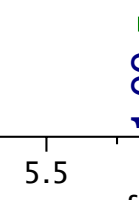

TाT

다남 ษ - लं

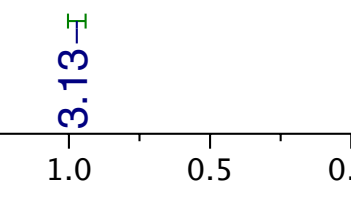

$11(\mathrm{ppm})$ 
$75 \mathrm{MHz}$

$\mathrm{CDCl}_{3}$

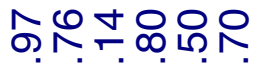

เి

กิ
ปี่
$\frac{8}{1}$

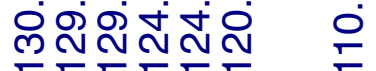

iा

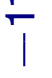

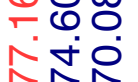

। I

ํํㅁ

으ํํㅇ

कீர்

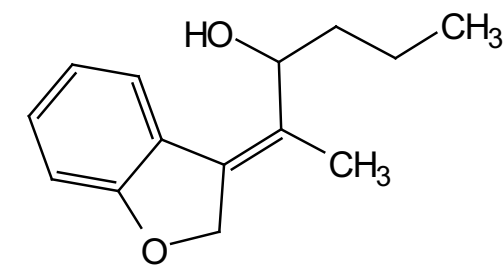

41
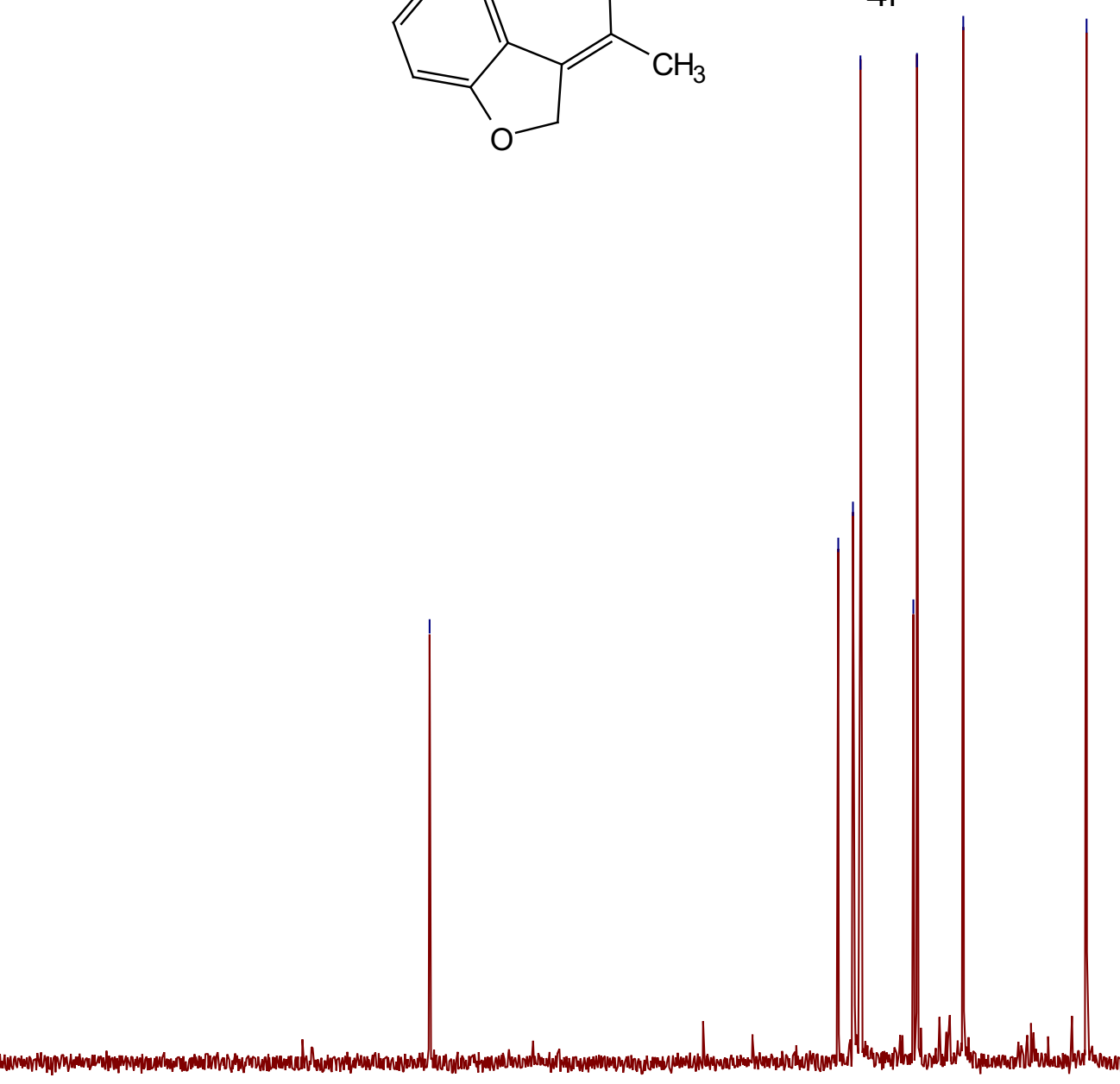


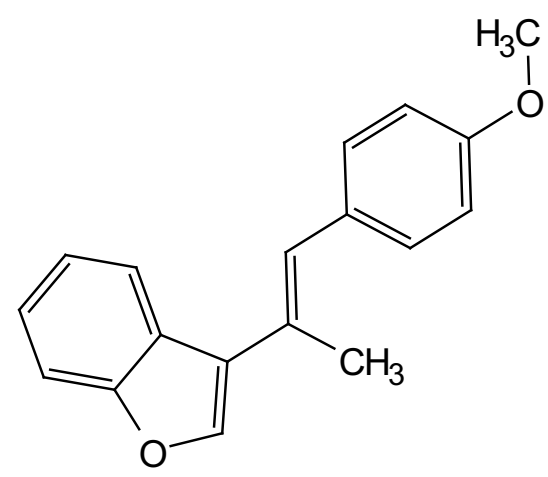

$5 a$

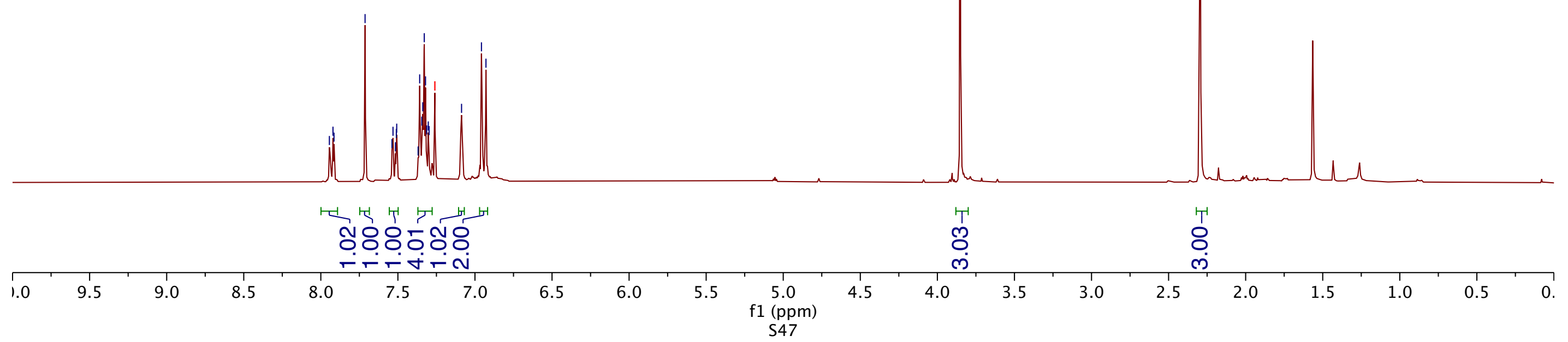


$75 \mathrm{MHz} \quad \mathrm{CDCl}_{3} \quad \frac{\mathrm{m}}{\mathrm{c}}$

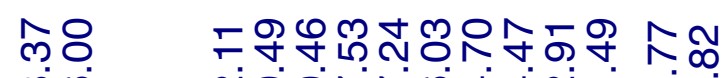

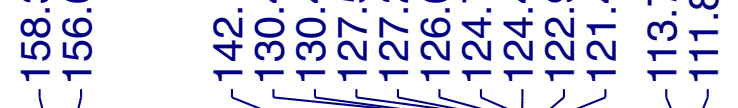

1)

$\stackrel{\infty}{\sim}$

เก

$\frac{9}{1}$

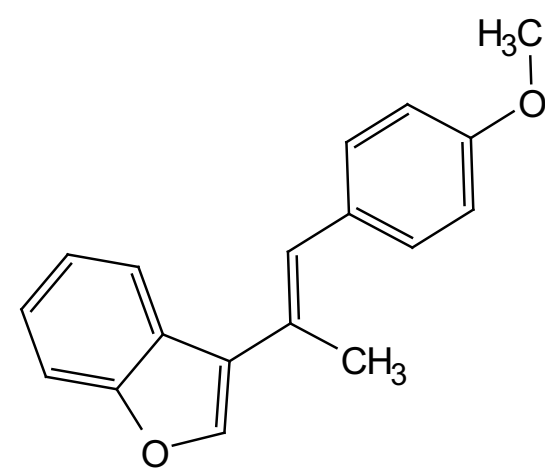

$5 a$

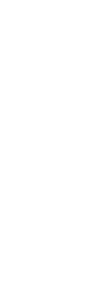




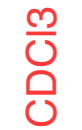

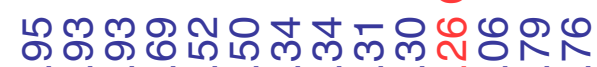

r N

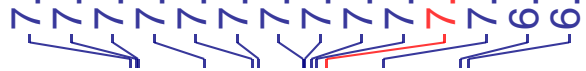

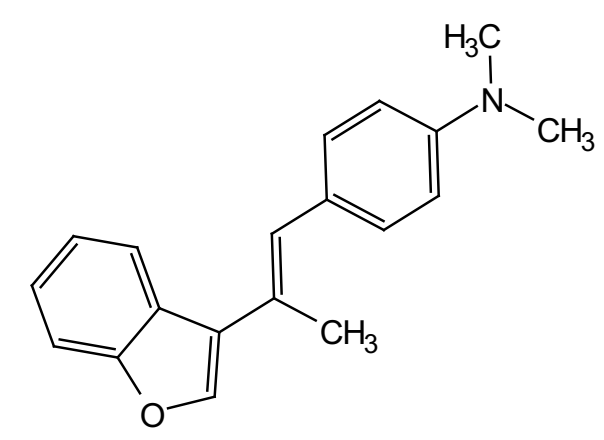

$5 m$

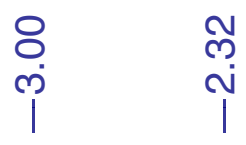

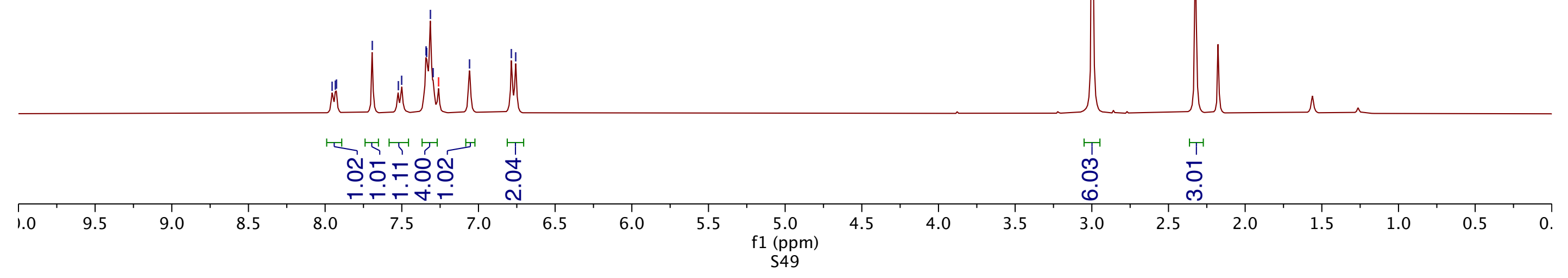




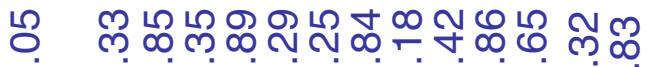

i

$\uparrow \uparrow \underbrace{-1 \tau}$<smiles>C/C(=C\c1ccc(N(C)C)cc1)c1coc2ccccc12</smiles> 

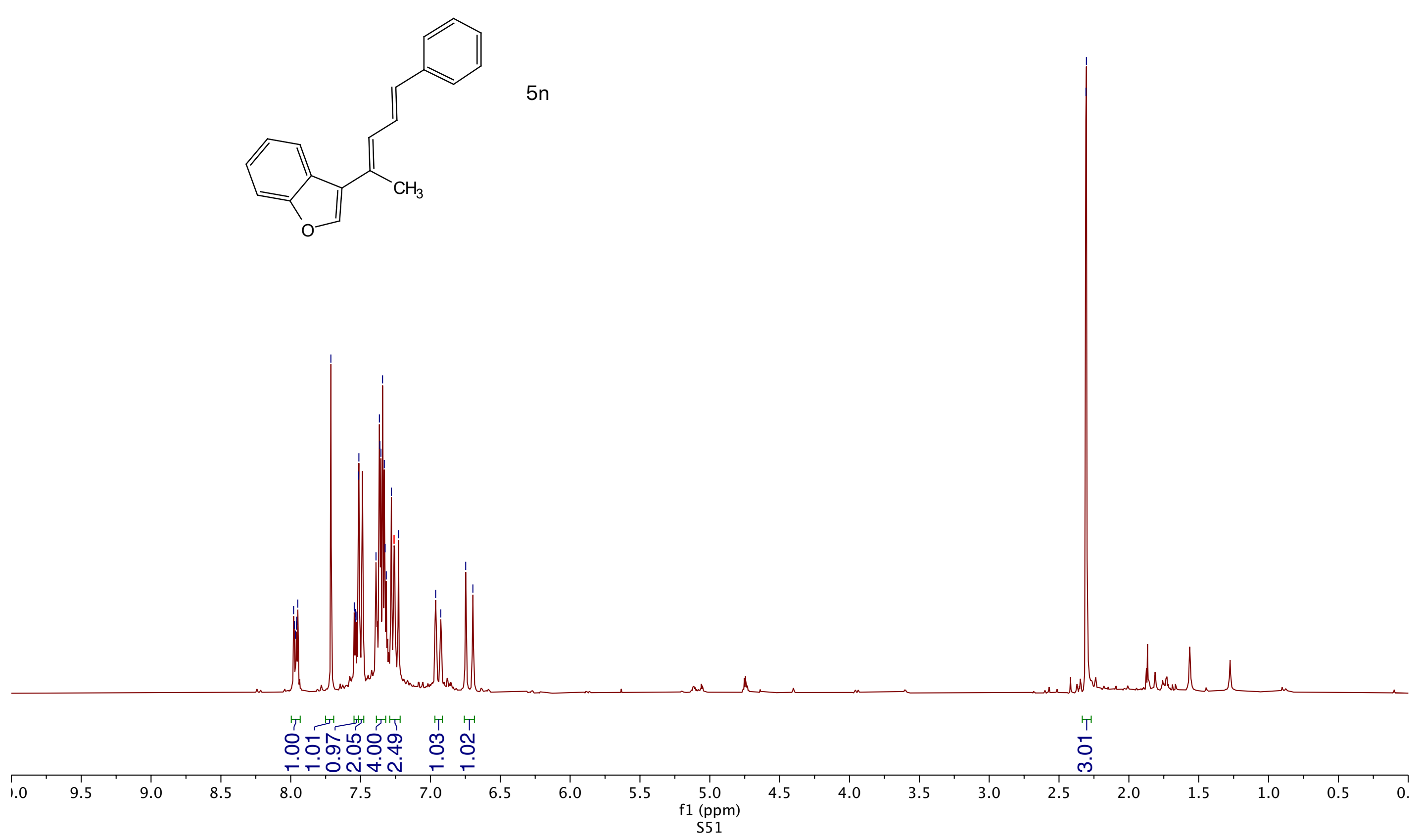


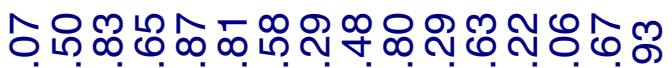

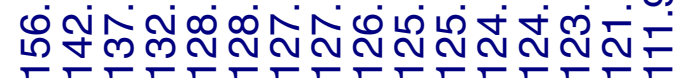
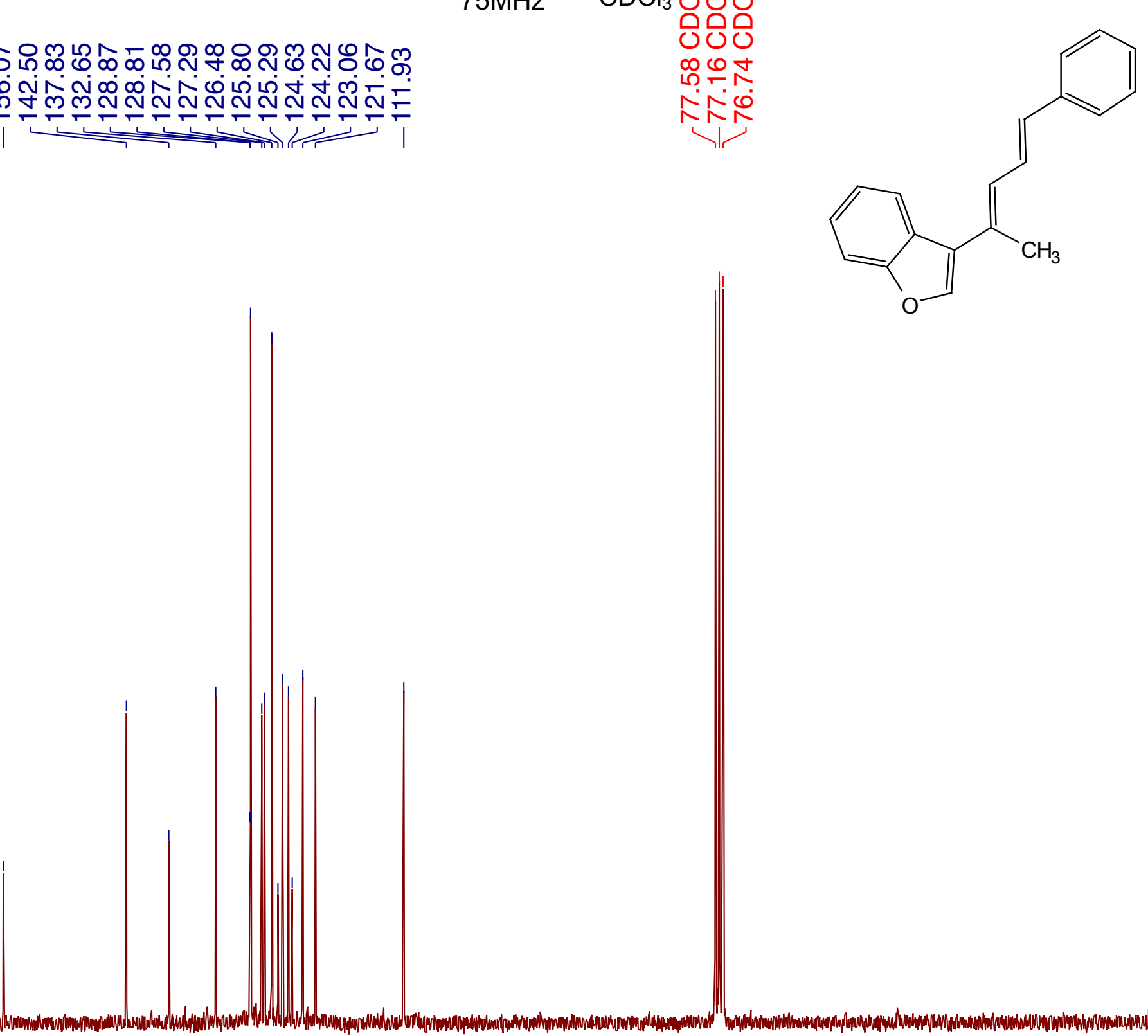
$\mathrm{CDCl}_{3}$

(土)6a endo

\begin{tabular}{|c|c|c|}
\hline ణ్లైలై & চ & $\stackrel{\infty}{1}$ \\
\hline ما & קं mु & $\stackrel{\sim}{i}$ \\
\hline
\end{tabular}
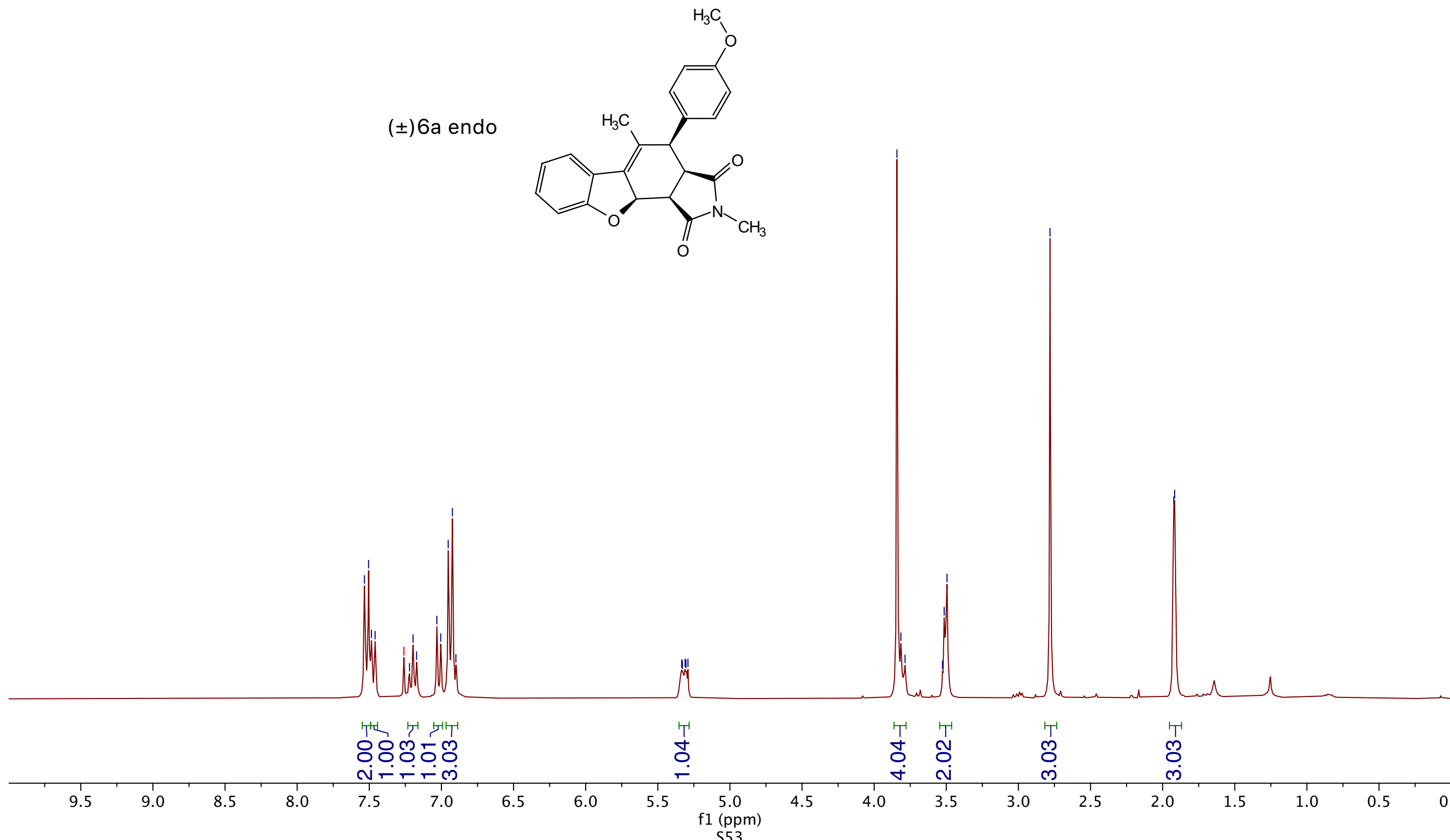
$\mathrm{CDCl}_{3} \frac{m}{\mathrm{v}} \frac{m}{\mathrm{O}}$

\begin{tabular}{|c|c|}
\hline$\therefore 8$ & ঙ. \\
\hline مْ & ஸ் \\
\hline
\end{tabular}

๑

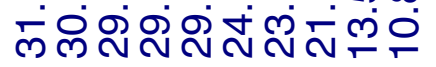

我

ปั

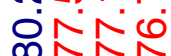

๓ి ๒กิญ

ก

$\stackrel{ }{\stackrel{0}{\circ}}$

(士)6a endo
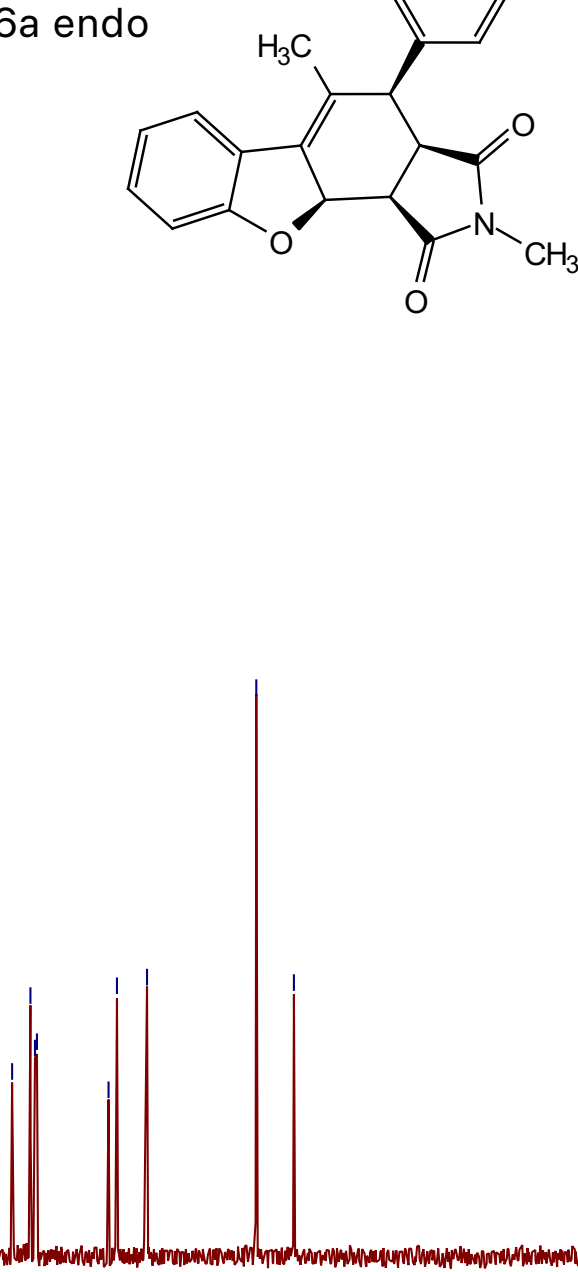


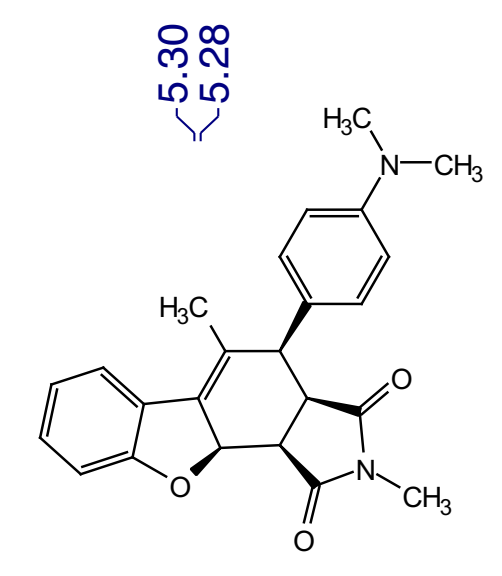

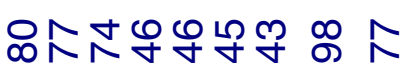
लुल

\section{ฮุ}

$( \pm) 6 \mathrm{~m}$ endo
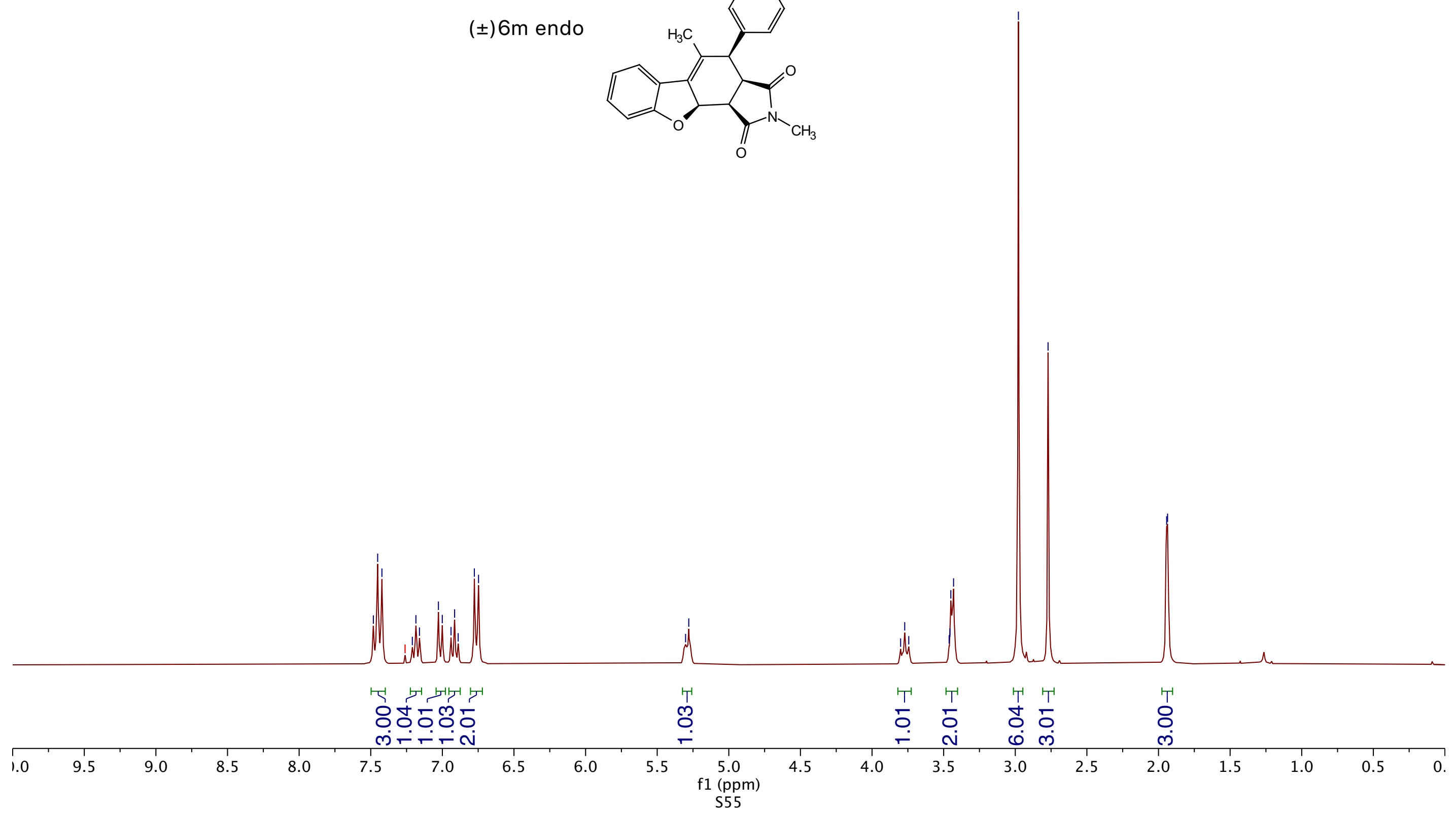
$75 \mathrm{MHz} \quad \mathrm{CDCl}_{3} \frac{m}{\mathrm{U}} \frac{m}{\mathrm{U}} \frac{m}{\mathrm{O}}$

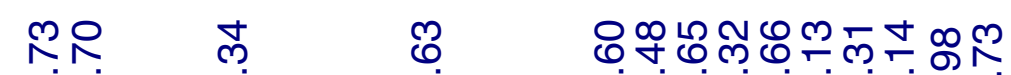

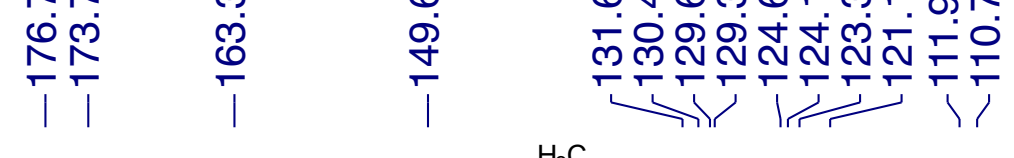

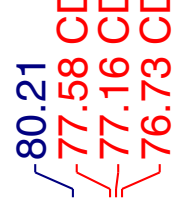

๘ִ

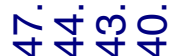

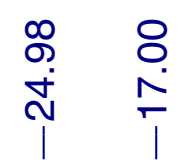

$( \pm) 6 \mathrm{~m}$ endo

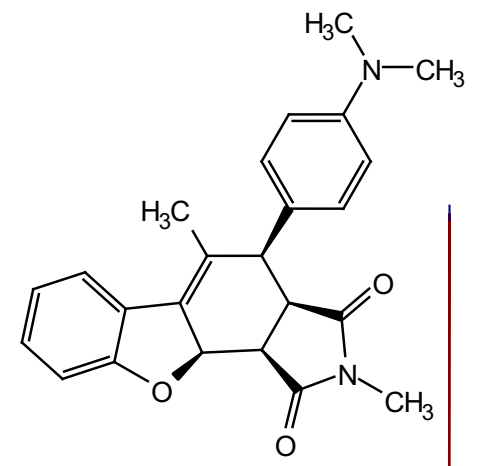

|र।

$\frac{1}{1}$




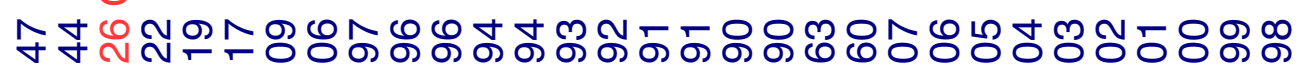

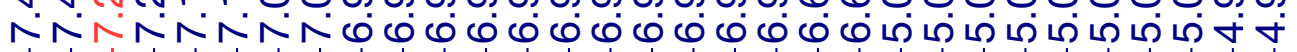

$( \pm) 7 \mathrm{~m} / 8 \mathrm{~m} 85 / 15$
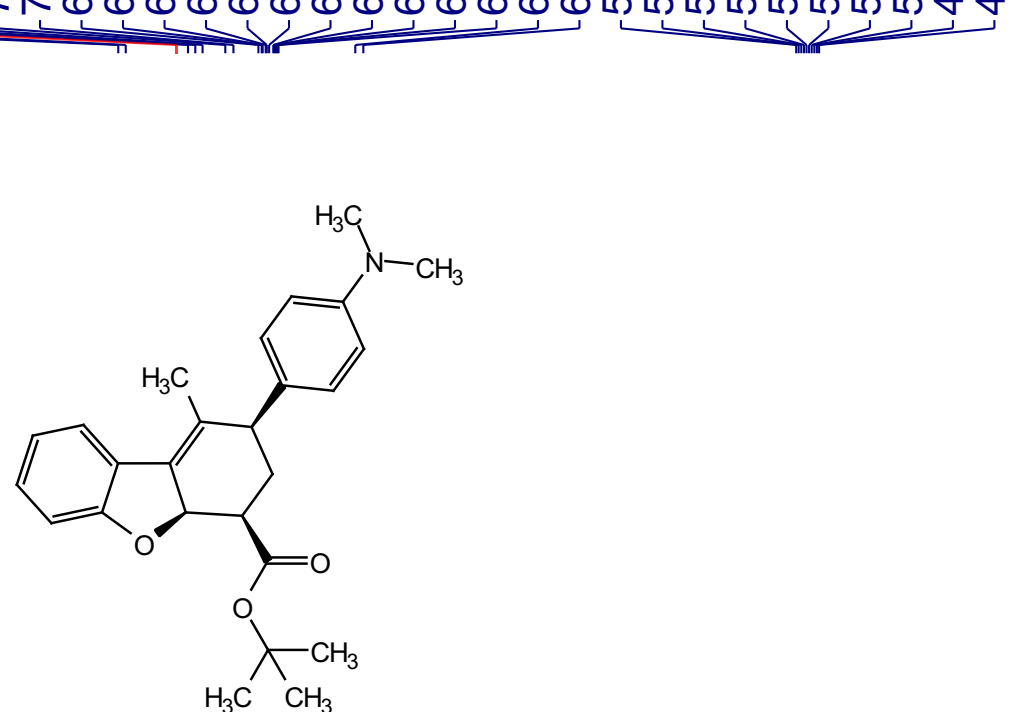

땅요 लं लं 4

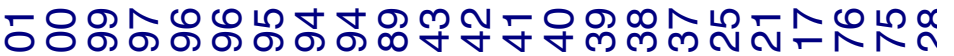

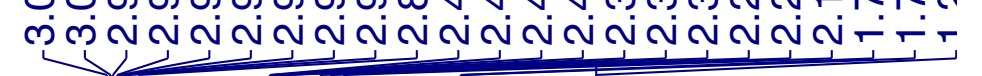




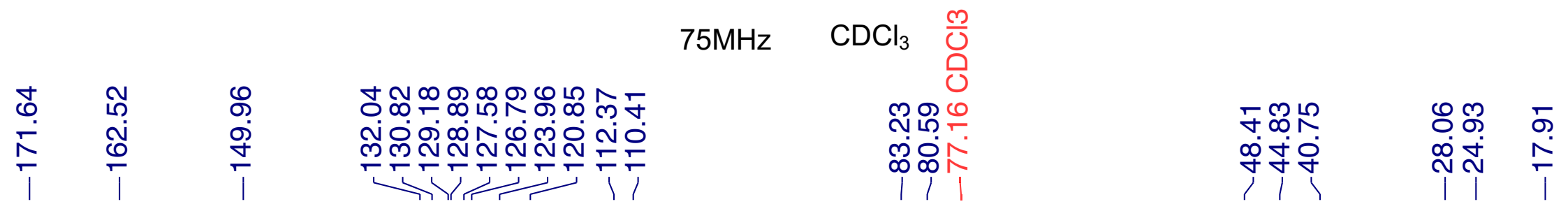

( \pm ) $7 \mathrm{~m} / 8 \mathrm{~m} 85 / 15$
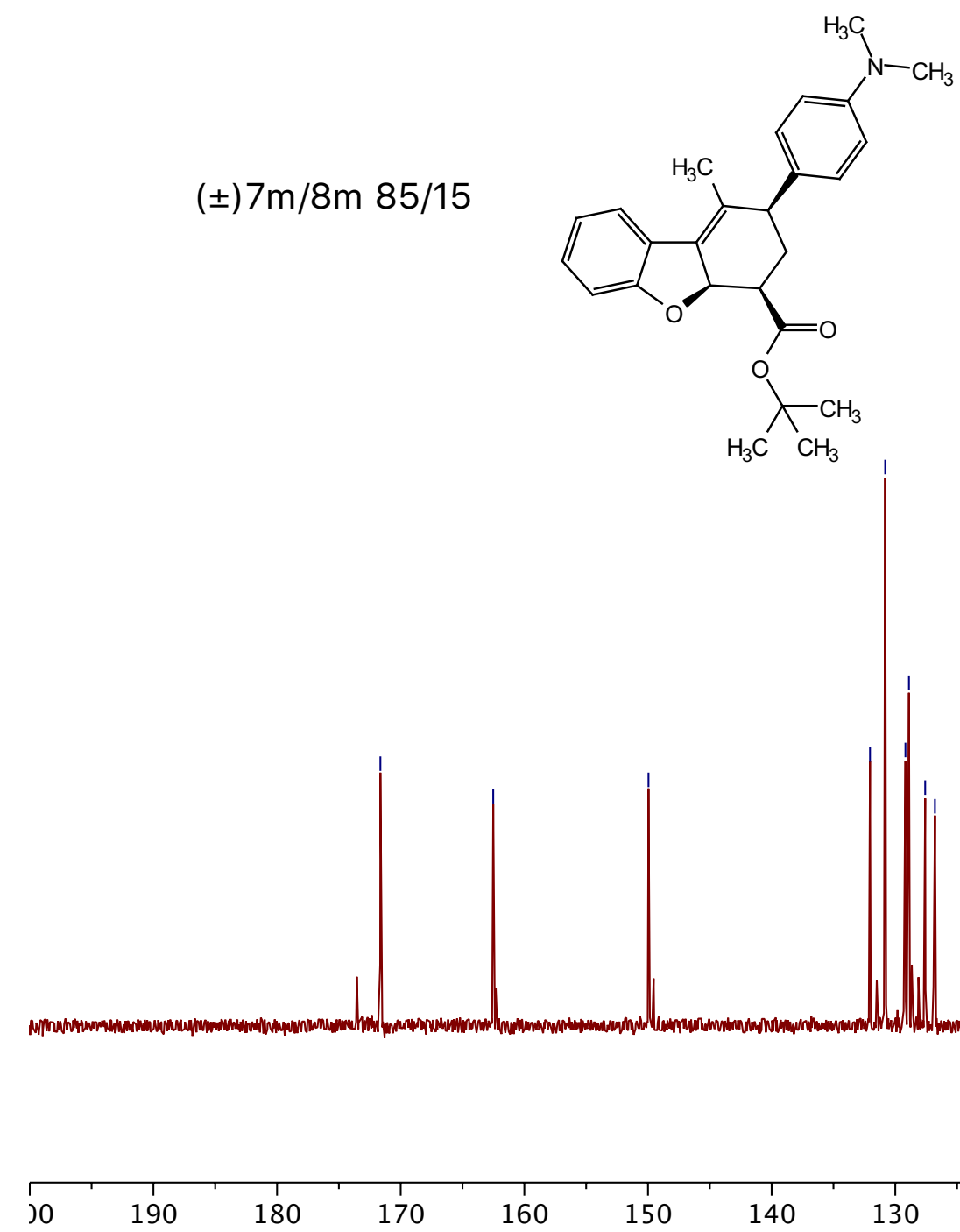


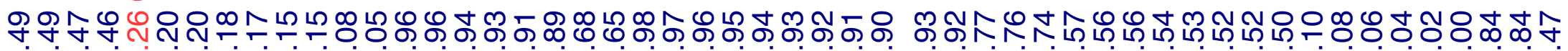

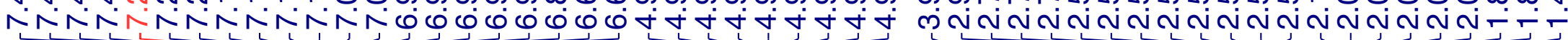

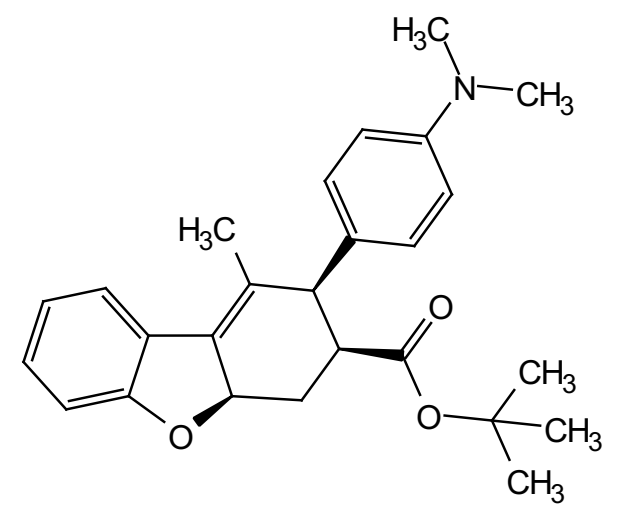

$( \pm) 8 m$ endo

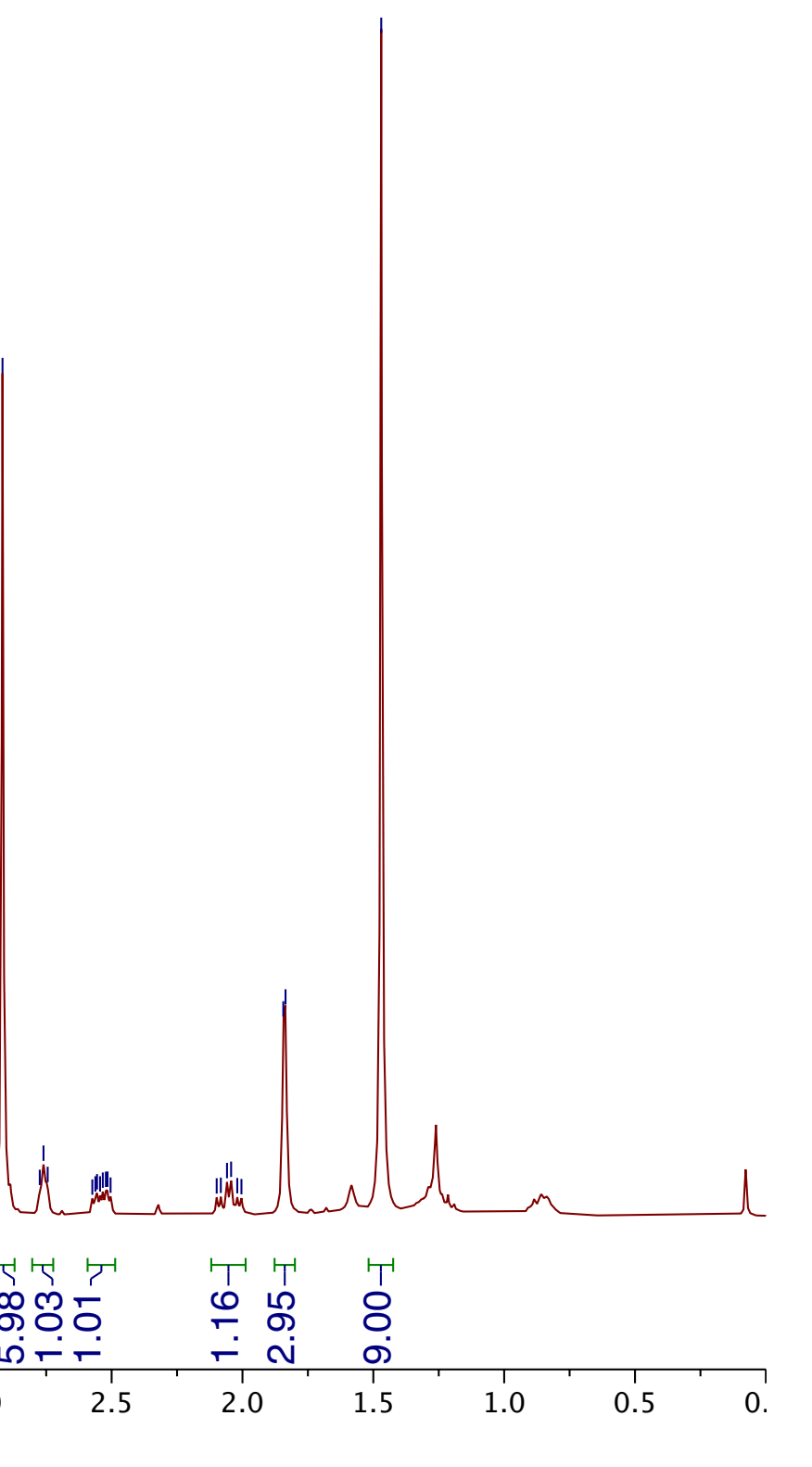


$75 \mathrm{MHz} \quad \mathrm{CDCl}_{3} \frac{\mathrm{m}}{\mathrm{v}} \frac{\mathrm{m}}{\mathrm{v}} \frac{\mathrm{m}}{\mathrm{O}}$

\begin{tabular}{|c|c|c|c|c|c|}
\hline $\begin{array}{l}\text { mे } \\
\stackrel{\mathrm{v}}{\emptyset} \\
\stackrel{1}{1}\end{array}$ & $\begin{array}{l}\infty \\
\stackrel{\infty}{\infty} \\
\stackrel{+}{+} \\
\end{array}$ & 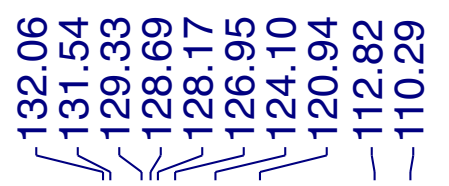 & 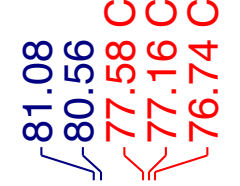 & 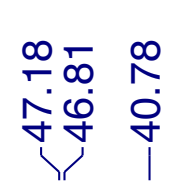 & $\begin{array}{l}\bar{\sim} \\
\infty \\
\stackrel{\infty}{\infty} \\
\stackrel{\infty}{\sim} \\
\mid\end{array}$ \\
\hline
\end{tabular}
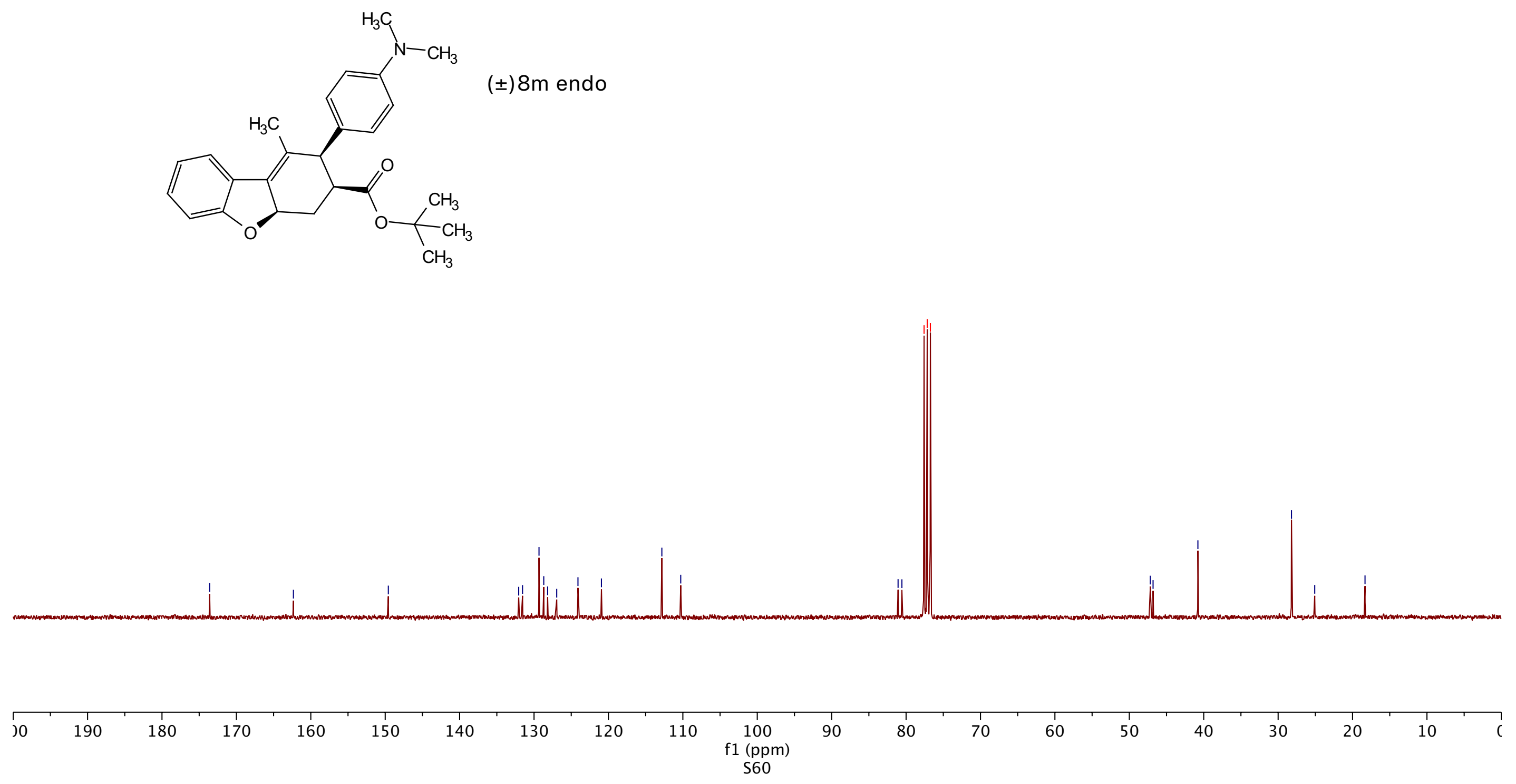